\title{
Astrocyte Differentiation of Human Pluripotent Stem Cells: New Tools for Neurological Disorder Research
}

\author{
Abinaya Chandrasekaran', Hasan X. Avci'1,2, Marcel Leist ${ }^{3}$, Julianna Kobolák' and \\ Andras Dinnyés ${ }^{1,4 *}$ \\ ${ }^{1}$ BioTalentum Ltd, Gödöllö, Hungary, ${ }^{2}$ Department of Medical Chemistry, University of Szeged, Szeged, Hungary, \\ ${ }^{3}$ Dorenkamp-Zbinden Chair, Faculty of Mathematics and Sciences, University of Konstanz, Konstanz, Germany, ${ }^{4}$ Molecular \\ Animal Biotechnology Laboratory, Szent Istvan University, Gödöllö, Hungary
}

\section{OPEN ACCESS}

Edited by:

Keith Murai,

McGill University, Canada

Reviewed by:

Benedikt Berninger,

University of Mainz, Germany

Andrew MacLean

Tulane University School of Medicine,

USA

Luisa Pinto,

University of Minho, Portugal

*Correspondence:

Andras Dinnyés

manuscript.dinnyes@biotalentum.hu

Received: 29 June 2016

Accepted: 30 August 2016

Published: 26 September 2016

Citation:

Chandrasekaran A, Avci HX, Leist M,

Kobolák J and Dinnyés A (2016)

Astrocyte Differentiation of Human

Pluripotent Stem Cells: New Tools

for Neurological Disorder Research.

Front. Cell. Neurosci. 10:215.

doi: 10.3389/fncel.2016.00215
Astrocytes have a central role in brain development and function, and so have gained increasing attention over the past two decades. Consequently, our knowledge about their origin, differentiation and function has increased significantly, with new research showing that astrocytes cultured alone or co-cultured with neurons have the potential to improve our understanding of various central nervous system diseases, such as amyotrophic lateral sclerosis, Alzheimer's disease, or Alexander disease. The generation of astrocytes derived from pluripotent stem cells (PSCs) opens up a new area for studying neurologic diseases in vitro; these models could be exploited to identify and validate potential drugs by detecting adverse effects in the early stages of drug development. However, as it is now known that a range of astrocyte populations exist in the brain, it will be important in vitro to develop standardized protocols for the in vitro generation of astrocyte subsets with defined maturity status and phenotypic properties. This will then open new possibilities for co-cultures with neurons and the generation of neural organoids for research purposes. The aim of this review article is to compare and summarize the currently available protocols and their strategies to generate human astrocytes from PSCs. Furthermore, we discuss the potential role of human-induced PSCs derived astrocytes in disease modeling.

Keywords: astrocyte, glial, central nervous system (CNS), Alzheimer disease (AD), brain pathology, microglia, CNTF, brain damage and repair

\section{INTRODUCTION}

Central nervous system neurons are never alone; they are often connected with astrocytes along with other cell types to form structural and functional networks. Astrocytes are the most abundant cell types in the CNS (Azevedo et al., 2009) with a remarkable heterogeneity both in morphology and function. In the past, astrocytes were believed to act as "passive support cells" for electrically

Abbreviations: $\mathrm{A} \beta$, amyloid-beta; $\mathrm{AD}$, Alzheimer's disease; ALS, amyotrophic lateral sclerosis; ApoE, apolipoprotein E; AQP-4, aquaporin-4; AxD, Alexander disease; BBB, blood-brain barrier; BMP, bone morphogen protein; CT-1, Cardiotrophin-1; CNS, central nervous system; CNTF, ciliary neurotrophic factor; DS, down syndrome; EAAT1 and EAAT2, excitatory amino acid transporter1/2; EBs, embryoid body; EOAD, early onset Alzheimer's disease; FGF-2 or bFGF, fibroblast growth factors; GFAP, glial fibrillary acid protein; GDH, glutamate dehydrogenase; GLT-1, glutamate transporter; GS, glutamine synthase; HE, hepatic encephalopathy; hESCs, human embryonic stem cells; iPSCs, induced pluripotent stem cells; iSVZ, inner SVZ; IL-6, interleukin-6; IPC, intermediate progenitor cells; LOAD, late onset-AD; LIF, leukemia inhibitory factor; MCTs, monocarboxylate transporters; MNs, motor neurons; NMO, neuromyelitis optica; oSVZ, outer SVZ; PSCs, pluripotent stem cells; RGs, radial glial; RGC, retinal ganglion cells; RA, retinoic acid; RF, rosenthal fibers; SPs, senile plaques; SHH, sonic hedgehog; SVZ, subventricular zone; SOD-1, superoxide dismutase; TCA, tricarboxylic acid cycle. 
active neurons and to be primarily responsible for cellular homeostasis of the CNS, but current research shows their active participation in many other processes such as the formation of neural networks, recycling of neurotransmitters, and detoxification (Nedergaard et al., 2003; Krencik and Ullian, 2013). Many other functions are also beginning to emerge as the research on astrocytes continues, and our understanding of their disease-relevant cellular functions in several diseases has already been revised. Here, we review the role of astrocytes, compare their in vivo and in vitro differentiation, and discuss the pathomechanisms of certain diseases in which they are involved.

\section{THE ROLE OF ASTROCYTES IN THE CNS}

Astrocytes play a direct and critical role in the developing CNS in maintaining an optimal environment for the normal development and function of neurons. Some examples of astrocytic functions include energy supply, the formation of the $\mathrm{BBB}$, and removal of toxins and debris (described below). Impairments in these functions, as well as physiological fluctuation in glutamate/ $\mathrm{K}^{+}$levels, can trigger or exacerbate neuronal dysfunction (Zhang et al., 2016). Based on their important and physiological role, it is not at all surprising that changes in astrocytes can directly affect the behavior of rodents (Franke and Kittner, 2001).

\section{Energy Supplies for Neurons}

One of the oldest known functions of astrocytes is to supply energy in the form of lactate to neurons. Glucose is mainly stored as glycogen in astrocytes, where it is metabolized to pyruvate and lactate and then transported via MCTs across the cell membrane. The transported lactate is then utilized by neighboring neurons and metabolized (Magistretti et al., 1999). Apart from glucose metabolism, astrocytes are also involved in glutamate uptake via two pathways. The first pathway involves the direct conversion of glutamate to $\alpha$-ketoglutarate through NAD-dependent oxidative deamination catalyzed by $\mathrm{GDH}$, and the second pathway is an ATP-requiring reaction in which ammonium is catalyzed by GS to yield glutamine. This glutamate-glutamine shuttle protects against the toxic effects caused by extracellular glutamate (Sonnewald et al., 1997).

\section{Maintenance of the Cellular Homeostasis of the Brain}

One essential function of astrocytes is to maintain brain homeostasis through multiple dynamic equilibrium adjustments, including water balance, ion distribution, glutamate buffering, and recycling (Wang and Qin, 2010; Coulter and Eid, 2012). High levels of synaptic glutamate can cause over-activation of neurons which may lead to excitotoxicity; thus rapid removal of extracellular glutamate from the synaptic cleft is essential for neuronal survival (Dong et al., 2009). This is accomplished by $\mathrm{Na}^{+}$dependent transporters on astrocytes, EAAT1 and EAAT2, respectively.

Apart from glutamate clearance, astrocytes can control cerebral glutamate levels (Stobart and Anderson, 2013).
Glutamate that is taken up by the astrocytes is converted to glutamine by GS, then later passed back to the synaptic terminal where it is converted back to glutamate (Danbolt, 2001; Parpura and Verkhratsky, 2012). There is increasing evidence that the uptake of glutamate also induces glycolysis in astrocytes, resulting in the production and secretion of lactate for the neighboring neurons (Ricci et al., 2009; Bélanger et al., 2011; Stobart and Anderson, 2013). This mechanism, the astrocyte to neuron lactate shuttle, regulates lactate delivery in an activitydependent manner (Pellerin et al., 1998; Stobart and Anderson, 2013).

\section{Formation and Maintenance of the Blood-Brain Barrier}

Together with endothelial cells and pericytes of the brain microvessels, astrocytes form the BBB, a physical diffusion barrier which restricts the exchange of most molecules between blood and brain (Abbott et al., 2006; Macvicar and Newman, 2015). Astrocytes are also involved in regulating cerebral blood flow by a $\mathrm{K}^{+}$siphoning mechanism, releasing $\mathrm{K}^{+}$onto blood vessels from their end-feet in response to neuronal activity (Paulson and Newman, 1987). It has been suggested that the release of prostaglandins from astrocytes results in increased $\mathrm{Ca}^{2+}$ that evokes vessel dilation (Zonta et al., 2003). Likewise, they are also involved in regulating $\mathrm{BBB}$ permeability from the bloodstream to brain parenchyma by the activation of tight junction proteins through NF-кB (Brown et al., 2003; Abbott et al., 2006). $\mathrm{BBB}$ defects are involved in many neuroinflammatory and neurodegenerative diseases, including multiple sclerosis, where the specialized brain endothelial cells which comprise the $\mathrm{BBB}$ are diminished, causing a loss of protective function during the progressive phase of disease (Weiss et al., 2009).

\section{Synapse Formation, Maintenance, and Pruning}

There is now abundant evidence to support the notion that astrocytes are actively involved in the formation and refinement of neural networks (Oberheim et al., 2006; Araque and Navarrete, 2010). During development, billions of neurons connect to form functional networks via synapses, with the control of synapse development by astrocytes highly conserved across species. A distinctive attribute of astrocytes in synapse formation is to increase the number of synaptic structures (dendritic spine) within the neural circuits (Ullian et al., 2001; Slezak and Pfrieger, 2003; Stevens et al., 2007; Stipursky et al., 2011; Clarke and Barres, 2013). The first evidence for astrocytes being involved in synapse formation came from the rodent RGC study, which showed that culture with astrocytes resulted in a 10-fold increase in excitatory synapse and synaptic functionality (Meyer-Franke et al., 1995). Later, in vitro studies confirmed that astrocytes can also instruct synapse formation for human neurons (Diniz et al., 2012).

Astrocytes are also involved in the refinement of the neural network by synaptic pruning - the elimination of extra synapses to increase the precision and efficiency of neural circuits (Clarke and Barres, 2013). The mouse retinogeniculate system, an excellent model system for studying synapse refinement and 
elimination (Hong and Chen, 2011), has been used to show that signals released from astrocytes in the postnatal brain induced the expression of the complement component $\mathrm{Clq}$ that executes synapse elimination by astrocytes via phagocytosis (Stevens et al., 2007). Notably, astrocytes employ this mechanism throughout the nervous system (e.g., in the uninjured brain or in response to glioma or trauma). However, further work is required to investigate the phagocytic pathway of astrocytes in human models.

\section{Communication between Astrocytes and Neurons}

Studying the direct communication between astrocytes and neurons is a rapidly expanding field of neuroscience. The term "tripartite synapse," was proposed 20 years ago to describe synaptic physiology involving astrocytes, in addition to preand post-synaptic neurons. In this context, astrocytes release neuroactive molecules (such as glutamate, ATP, nitric oxide, prostaglandins, and D-serine) in the presence of elevated $\mathrm{Ca}^{2+}$, which in turn influence neuronal excitability (Araque et al., 1999; Perea et al., 2009; Eroglu and Barres, 2010).

The concept of "gliotransmission," which was first hypothesized in the 1980s, involves the active vesicular release of neurotransmitters and glutamate by astrocytes (Halassa et al., 2007). In other words, the GPCR-mediated $\mathrm{Ca}^{2+}$ variations in astrocytes can trigger the release of glutamate, D-serine, and ATP. So far, various mechanisms have been proposed for gliotransmission, including $\mathrm{Ca}^{2+}$-regulated vesicular exocytosis (Agulhon et al., 2012) and non-vesicular release. Additionally, Santello et al. (2011) found that cytokines are required for functional glutamatergic gliotransmission. While the importance of gliotransmission is supported by findings that dysfunction of astrocytic proteins involved in transmitter release can cause severe brain disorders (Rossi et al., 2011), there are still several features of gliotransmission that are controversial and require further clarification (Hamilton and Attwell, 2010; Sahlender et al., 2014; Sloan and Barres, 2014).

\section{CLASSIFICATION OF ASTROCYTES: A HETEROGENIC GROUP OF CELLS}

Astrocytes can exist in two distinct developmental stages: a highly proliferative state, which occurs within the developing brain in the first weeks after birth, or a mature state/postmitotic astrocytes (Ge et al., 2012). The peculiar morphology of mature mammalian astrocytes was first observed in mice by Otto Deiters in 1865 using chromic acid and carmine red staining (Deiters and Guillery, 2013). A detailed morphological study achieved by Camillo Golgi and Ramón y Cajal, who developed the black staining reaction and produced drawings of stained glial cells in 1872, revealed the distinct morphological pattern of the protoplasmic and fibrous astrocytes. These cells were first called "astrocyte" in 1893 by Mihály Lenhossék, a Hungarian anatomist and histologist, who stated that astrocytes are a mixed population of cells and not a single cell type. Based on our current understanding, there are a range of astrocyte subtypes differing in their cellular morphologies and anatomical locations in the brain (summarized in Table 1). Astrocyte morphologies vary considerably amongst cortical regions and display distinct biochemical/biophysical properties throughout discrete regions of the cortex (Emsley and Macklis, 2006; Regan et al., 2007). Due to their diversity, developing a full characterization of astrocytes is challenging.

\section{IDENTIFICATION OF ASTROCYTES}

The identification of astrocytes in vivo is usually based on staining of the cells for their content of GFAP. This microfilament protein shows a high specificity for astrocytes in brain tissue. As it is expressed in virtually all reactive astrocytes, it is particularly useful for identification of astrocytes in diseased brain. On the basis of such studies, it is known that the cells can change their morphology if they are activated or form scars (Anderson et al., 2016), but in general they display a typically stellate morphology. Rodent studies have shown that GFAP expression is not essential for astrocytes, and that subpopulations of resting astrocytes do not express the microfilament protein (Kuegler et al., 2012). As also subpopulations of resting human astrocytes may not stain for GFAP, their morphology is yet little characterized, and new markers are urgently needed (Zhang et al., 2016). The capacity of astrocytes to change shape is also obvious in vitro. If pure populations are cultured under standard conditions, cells are found to be flat and of a roughly polygonal or feathery shape, but if astrocytes are co-cultured with neurons, they can assume a stellate shape. Whilst most of the studies on astrocyte cultures were based on the rodent, Guillemin et al. (1997) isolated and characterized astrocytes from primate brain to study the differences between human and non-human primate CNS. Later it was confirmed that in vivo primate astrocytes have a stellate morphology, and express high levels of GFAP (Oberheim et al., 2009). Further, it was found that transient acidification of the culture media resulted in stellation of cultured primate astrocytes, accompanied by an increased expression of GFAP and vimentin (Renner et al., 2013). Although the non-human primate brain is an important model system essential for studying the primate brain, it is important to test whether the results can be generalized to the human brain, especially in the context of human diseases. Some of the markers that start to appear in both in vitro and in vivo are described below. The first indication of the glial specification is marked by induction of nuclear factor NFIAA/B and GLAST (Araque and Navarrete, 2010) which appears in embryonic development at E11.5 in the mouse. Both of these markers remain expressed during glial precursor migration. Furthermore, GLAST is also expressed in the RG cells. Other markers such as S100 $\beta$, FGFR3, FABP7, BLBP, and SOX9 (which are required for the neuron-glial switch) are not exclusive, astrocyte-committed markers but are expressed during neurogenic stages. For instance, while S100 $\beta$ is an astrocyte progenitor marker, it is also expressed in oligodendrocytes progenitors (Deloulme et al., 2004; Hachem et al., 2005). A fascinating issue in this field is how to identify a mature astrocyte and how to standardize this definition worldwide, 
TABLE 1 | Classification of astrocytes.

\begin{tabular}{|c|c|c|c|c|}
\hline $\begin{array}{l}\text { Types of } \\
\text { astrocytes }\end{array}$ & Anatomical locations & Cellular morphologies & Functions & Reference \\
\hline $\begin{array}{l}\text { Protoplasmic } \\
\text { astrocytes }\end{array}$ & Grey matter & $\begin{array}{l}\text { Short branched; } \\
\text { Thick processes }\end{array}$ & $\begin{array}{l}\text { - Maintenance of the } \\
\text { blood-brain barrier; } \\
\text { - Regulation of blood flow; } \\
\text { - In synapse formation; } \\
\text { - Neuronal metabolism }\end{array}$ & $\begin{array}{l}\text { Peters et al., 1991; } \\
\text { Bushong et al., 2002; } \\
\text { Nishiyama et al., 2002; } \\
\text { Ogata and Kosaka, 2002; } \\
\text { Oberheim et al., 2006; } \\
\text { Sofroniew and Vinters, } 2010\end{array}$ \\
\hline Fibrous astrocytes & White matter & Thin and straight processes & $\begin{array}{l}\text { - Maintenance of the } \\
\text { blood-brain barrier; } \\
\text { - Regulation of blood flow; } \\
\text { - In synapse formation; } \\
\text { - Neuronal metabolism }\end{array}$ & Sofroniew and Vinters, 2010 \\
\hline $\begin{array}{l}\text { Interlaminar } \\
\text { astrocytes }\end{array}$ & $\begin{array}{l}\text { Pial surface (humans } \\
\text { and monkey) }\end{array}$ & Spherical cell bodies & $\begin{array}{l}\text { - Regulation of calcium wave; } \\
\text { - Thick network of GFAP fibers }\end{array}$ & Oberheim et al., 2009 \\
\hline $\begin{array}{l}\text { Varicose projection } \\
\text { astrocytes }\end{array}$ & $\begin{array}{l}\text { Fifth and sixth layer of } \\
\text { the cerebral cortex }\end{array}$ & $\begin{array}{l}\text { Long processes. (up to } \\
1 \mathrm{~mm} \text { in length) }\end{array}$ & Unknown & $\begin{array}{l}\text { Oberheim et al., 2009, } \\
2012\end{array}$ \\
\hline $\begin{array}{l}\text { Epithelial glial cells } \\
\text { (Bergmann glia) }\end{array}$ & $\begin{array}{l}\text { Purkinje-cell layer of } \\
\text { cerebellum }\end{array}$ & Long processes & - Synaptic transmission. & $\begin{array}{l}\text { Fuller and Burger, 1992; } \\
\text { Olude et al., } 2015\end{array}$ \\
\hline Fañanas cells & Cerebellar cortex & Feather-like arrangement & Unknown & Fuller and Burger, 1992 \\
\hline Müller cells & Retina of juvenile & A type of radial glial & $\begin{array}{l}\text { - Retinal homeostasis; } \\
\text { - Phagocytosis of neural debris; } \\
\text { - Metabolic activity; } \\
\text { - Glycogen within their } \\
\text { cytoplasm }\end{array}$ & $\begin{array}{l}\text { Fuller and Burger, 1992; } \\
\text { Vecino et al., } 2015\end{array}$ \\
\hline Pituicytes & Neurohypophysis & Irregular shaped cytoplasm & Unknown & Burger and Scheithauer, 1993 \\
\hline $\begin{array}{l}\text { Interstitial } \\
\text { epiphyseal cells }\end{array}$ & Epiphysis & Cytoplasmic processes & Unknown & Fuller and Burger, 1992 \\
\hline
\end{tabular}

Astrocytic domain organization varies with pathology and anatomical locations.

and two laboratories are notable for their work in this area (Krencik et al., 2011; Roybon et al., 2013). One of the hallmarks of astrocyte identification is GFAP, the major interfilamentous protein of a mature astrocyte (Fox et al., 2004). However, while the expression pattern of GFAP is a sensitive, reliable marker for most of the reactive astrocytes that respond to CNS injuries, additional markers such as AQP-4, GS, GLT-1, and GLAST-1 should also be used to study astrocyte differentiation (Kuegler et al., 2010; Krencik and Zhang, 2011; Krencik and Ullian, 2013; Kleiderman et al., 2016). A new astrocytic early stage marker, ALDH1, that selectively labels cortical astrocytes in vivo has recently been discovered (Rowitch and Kriegstein, 2010) in vivo, and ALDH1A1 expression has been demonstrated to serve as a reliable marker in early astrocytic differentiation (Alexandra Adam et al., 2012). Table 2 summarizes our current knowledge of astrocyte-specific markers in both human and mouse. For instance, during early development, immature astrocytes express mainly vimentin while at the end of gestation period vimentin is replaced by GFAP in differentiated astroglial cells. However, additional studies are still needed to clarify the complex roles of astrocytes.

Astrocytogenesis can also occur in neurogenic hot spots, correlated with the production of new neurons. In adult rodent brain, neurogenesis occurs in the SVZ of the lateral ventricle and the subgranular zone (SGZ) of the hippocampal dentate gyrus (Ma et al., 2009). Observations that cells with astrocytic markers (GFAP and S100ß; Zhang and Jiao, 2015) begin to emerge in the granular cell layers of the dentate gyrus (Doetsch et al., 1997; Kriegstein and Gotz, 2003) are providing new insights into adult neurogenesis. Moreover, inflammatory and pathological changes may result in the conversion of astrocytes to neural stem cells. Whether this also applies to the human brain requires further investigation (Robel et al., 2011; Dimou and Götz, 2014; Götz et al., 2015).

\section{ORIGIN OF ASTROCYTES}

Gliogenesis generally follows neurogenesis in the developing brain. Our knowledge on "origin and lineage progression of human RG" has mainly been extrapolated from rodent studies due to the limited access of human brain tissue, but recent studies have begun to uncover unique structural and cellular features of the primate brain (Duan et al., 2015). The human neocortex contains around 16 billion neurons of diverse subtypes (Lui et al., 2011). As the neuroepithelial cells expand the cortical plate, they form an elongated bipolar cell type, RG cells (Ming and Song, 2005). Transformation of neuroepithelial cells into RG emerges 
TABLE 2 | List of human and mouse astrocyte markers.

\begin{tabular}{ll}
\hline Marker Name & Role/Localization \\
\hline Aldolase C (Fructose-bisphosphate aldolase C) & Targets glycolysis
\end{tabular}

\begin{tabular}{|c|c|}
\hline Aquaporin-4 & Perivascular membranes of astrocytes \\
\hline
\end{tabular}

\section{Reference}

Li et al., 2013;

Roybon et al., 2013

Gee and Keller, 2005;

Kuegler et al., 2010;

Roybon et al., 2013;

Kleiderman et al., 2016

A2B5 (c-series ganglioside-specific antigen)

Astrocyte precursors and type 2 astrocytes

Dietrich et al., 2002;

Kuegler et al., 2010;

Hayashi et al., 2011;

Kleiderman et al., 2016

Aldehyde dehydrogenase family 1 member L1

ALDH1L1 and GLT1 are co-expressed in the same population of astrocytes; Appears at mid-embryogenesis

Cahoy et al., 2008; Rowitch and Kriegstein, 2010; Roybon et al., 2013

\begin{tabular}{ll}
\hline Bystin & Stains reactive astrocytes \\
\hline Connexin 43 & Astrocyte specific marker in the human brain
\end{tabular}

Glial fibrillary acid protein

Low GFAP at a quiescent state and High GFAP in mature state

Sheng et al., 2004

Lovatt et al., 2007;

Fatemi et al., 2008

Ghandour et al., 1980; Rodnight et al., 1997;

Kuegler et al., 2010;

Roybon et al., 2013;

Kleiderman et al., 2016

GLT-1* Early astrocytes; Postnatal marker

GLAST $1 \quad$ Mature astrocytes; Appears at mid-embryogenesis

Chaudhry et al., 1995; Kuegler et al., 2010;

Roybon et al., 2013;

Kleiderman et al., 2016

Kuegler et al., 2010;

Roybon et al., 2013;

Kleiderman et al., 2016

\begin{tabular}{|c|c|c|}
\hline Nuclear factor $1 \mathrm{~A}$ & Gliogenic switch & Roybon et al., 2013 \\
\hline Nestin & Reactive glial cells & Classic marker \\
\hline Glycogen phosphorylase & Astrocyte specific marker in the human brain & Pfeiffer et al., 1992 \\
\hline $\mathrm{S} 100 \beta$ & Early astrocyte marker & $\begin{array}{l}\text { Burette et al., 1998; } \\
\text { Carlén et al., 2009; } \\
\text { Kuegler et al., 2010; } \\
\text { Kleiderman et al., } 2016 .\end{array}$ \\
\hline Vimentin & Canonical marker & $\begin{array}{l}\text { Deneen et al., 2006; } \\
\text { Roybon et al., } 2013\end{array}$ \\
\hline
\end{tabular}

Based on the available data, this simplified table shows the identified astroglial markers in current trend. The onset of expression varies in different regions of the CNS.

* in rodents: Excitatory amino acid transporter 2.

at the beginning of neurogenesis and occurs in humans over the course of months, while the process only takes "days" in the rodent brain (Pollen et al., 2015). RG can be distinguished from neuroepithelial progenitors by the expression of astroglial markers.

\section{Radial Glial Division}

Radial glial are the earliest cells to be derived from the lateral wall of the neural tube (Anthony et al., 2004; Howard et al., 2006; Mo et al., 2007) (Figure 1). In humans, RG cells are also found in the oSVZ in the developing neocortex, which is absent in rodents (Pollen et al., 2015). The oSVZ contains a large proportion of outer RG (oRG) cells that act as guides for neuronal migration. Particularly in humans, the oRG cells appear to contribute to neocortical expansion by increasing the number of neural precursor cells (NPCs) (LaMonica et al., 2013).

Radial glial cells usually divide at the apical (ventricular) surface within the ventricular zone (VZ) to generate new neurons or single IPC by asymmetric division, or self-amplify progenitors by symmetric division. The majority of these progenitors migrate 


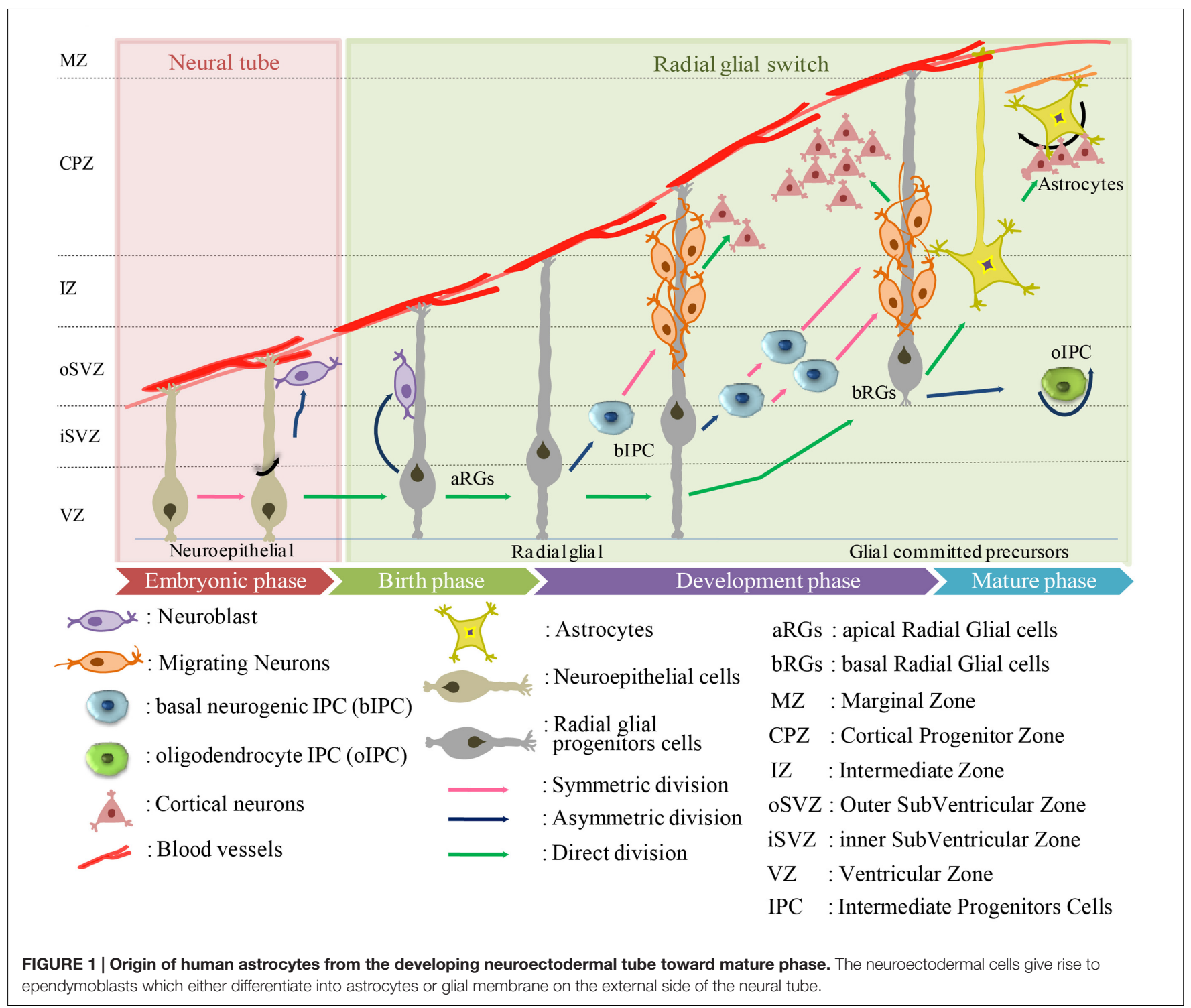

radially with the rapid increase in the width of the cerebral wall (Hartfuss et al., 2001; Marín and Rubenstein, 2001; Anthony et al., 2004; Götz and Huttner, 2005; Sild and Ruthazer, 2011; Florio and Huttner, 2014; Schitine et al., 2015). Just before birth, the RGs "accelerate the expansion of the neuronal population" and switch to gliogenesis to produce astrocytes. This transition from neurogenesis to astrogenesis is mediated by known soluble factors including IL-6 and BMP-4 protein (Miller and Gauthier, 2007). By the end of the cortical development, most of the RG cells lose their ventricular attachments and migrate toward the cortical plate to form different cortical layers.

In general, there is a remarkable overlap in the expression patterns and cell proliferative processes of human and rodent, but there are species differences in structural organization and complexity. In mice, the majority of cells form a single compact layer, whereas in humans they are dispersed throughout a larger zone. IPCs in human VZ regions can be divided into two subpopulations, apical and basal, that have discrete molecular profiles. Apical IPCs are defined by mitosis occurring at the ventricular surface and the basal IPCs are defined by mitosis occurring at an aventricular location and the absence of ventricular contact (Florio and Huttner, 2014). In general, IPCs can generate neurons (nIPCs) or glial cells, including oligodendrocytes (oIPCs) or astrocytes (aIPCs). Mouse IPC go through only one round of cell division to produce two neurons (LaMonica et al., 2013), whereas human IPC undergo several rounds of cell division before producing neurons (Hansen et al., 2010). The molecular mechanisms that underlie IPC division are still not clear but their transcriptional regulators, such as TBR2, EOMES are likely involved (Kowalczyk et al., 2009; Fietz et al., 2010; Hansen et al., 2010). Many reports have suggested that SVZ in humans can be subdivided into the iSVZ and oSVZ (Hansen et al., 2010; Lewitus et al., 2013; Thomsen et al., 2016). A new type of outer radial glia-like cells, basal RGs (bRGs), 
was identified in the oSVZ of developing cortices of humans (Betizeau et al., 2013; Pilz et al., 2013). The translocation of RG cells and differentiation to astrocytes has been visualized through time-lapse imaging (Noctor et al., 2008), as well as a similar transformation in the sub-cortical telencephalon (Barry and McDermott, 2005). To date, five different sources of cortical astrocytes have been identified: (i) RG cells within the ventricular zone; (ii) RG cell transformation; (iii) intermediate progenitors; (iv) glial progenitors in marginal zone; and (v) superficial layer progenitors. However, only a limited number of studies on astrogliogenesis have been performed in the human (Kanski et al., 2014; Paşca et al., 2015), in contrast to the numerous reports on rodents (Chi et al., 2006; Ventura and Goldman, 2007; Widestrand et al., 2007; Demars et al., 2010; Ge et al., 2012).

\section{MOLECULAR TRIGGERS AND REGULATORS}

Before moving on to consider human astrocyte development in vitro to generate authentic human astrocytes, we must first consider the in vivo mechanism.

Inside a human cortex, each astrocyte can be connected to several thousand neurons to form the neural network. For instance, each astrocyte can associate with the neural process to form many neuronal synapses $(2,000,000$ in humans) (Oberheim et al., 2009). Astrogenesis is mainly initiated by the activation of JAK-STAT, the canonical pathway regulating astrocyte gene expression (Bonni et al., 1997), although multiple signaling pathways participate (Wen et al., 2009). For example, STAT3 signaling is crucial for astrogenesis, and STAT3 activation requires the presence of the p300/CBP co-activator complex to initiate astrocyte gene expression (Freeman, 2010). STAT3 is activated by tyrosine kinases belonging to the Src and JAK families. This occurs as a consequence of cytokine or growth factor receptor activation and has been shown to be relevant for the EGF receptor (epidermal growth factor receptor), the GCSF (granulocyte colony stimulating factor) receptor or the IL-6 and CNTF receptors (Moon et al., 2002; Freeman, 2010). In addition to STAT3, the Notch pathway is another important regulator of cell fate. Notch activation directly regulates the HES family of the $b H L H$ gene, inhibiting neurogenesis during the neurogenic period and promoting astrogenesis during the gliogenic period (Kageyama et al., 2005, 2008). Other signaling pathways, such as BMP-SMAD, and Nuclear factor IA (NFIA) can also promote astrogenesis in the presence of an active JAK-STAT signal (Bonni et al., 1997; Nakashima et al., 2001; Deneen et al., 2006; Nagao et al., 2007; Nakanishi et al., 2007; Stipursky et al., 2012). Even though the mechanisms underlying mammalian astrocyte commitment have not fully been characterized, this work has shed light on the essential signaling pathways that are responsible for the transition.

A combination of several molecules such as TGF-alpha, CNTF, LIF, IL-6 cytokines, and oncostatin $M$ are required for astrocyte stimulation in vivo. Other factors such as BMPs are also involved in determining astrocytic fate. For instance, a delay or disruption in any of the signaling pathways can hinder the epigenetic mechanism and timing of neurogenesis and astrogenesis, eventually leading to perturbations in the relative ratios of the cell types (Yan et al., 2005; Tidyman and Rauen, 2009).

\section{Generation of Human Astrocyte from Pluripotent Stem Cells}

Examination of human astrocytes from post-mortem tissue have led to a better understanding of brain diseases and opened doors toward generating more efficient in vitro based models. The first human astrocytes were cultured from fetal or adult postmortem tissue (Ennas et al., 1992; Lee et al., 1993), but were often contaminated with microglia and other cell types which were difficult to separate during dissections. Additionally, in many cases, biopsies represent the end stage of the disease and control tissue is obviously inaccessible due to ethical concerns and potential health risks. Given all the practical limitations of human brain tissue research, murine and rat astrocytes have mostly been used to study astrocyte physiology. For this purpose, murine or rat astrocytes are usually purified from the cortex. Alternatively, astrocytes may be generated from murine PSCs (Kleiderman et al., 2016). These generalized approaches do not account for regional heterogeneity of astrocytes, such as the expression of the transporter OCT3, which is high in striatal astrocytes and low in cortical astrocytes (Cui et al., 2009). Especially for disease studies, astrocytes may therefore be purified from the relevant brain regions. For instance, cerebellar, cortical, striatal, and nigral astrocytes show differences in dopamine or angiotensin signaling (Yu et al., 1996; Reuss and Unsicker, 2000). Thus, astrocytes from specific brain regions offer an attractive alternative source to study astrocyte function in vitro. Mice models offer further advantages since methods to manipulate the genome (knock-out or knock-in genes) are well-established. With these approaches it needs, however, to be considered that astrocyte heterogeneity may not be a cellintrinsic property, but be decided by the surrounding neurons, and may therefore get lost in cell culture (Farmer et al., 2016).

\section{Comparison of Human and Rodent Astrocytes}

The long list of interspecies variation between human and rodent astrocytes underlines the need for authentic human astrocytes for disease modeling. Importantly, there are several visible differences between rodent and human astrocytes:

\section{(i) The average length of astrocytes}

Human astrocytes are structurally more complex than mouse astrocytes (Oberheim et al., 2006, 2009). An investigation of the total arborization length of mouse and human astrocytes in vitro found that the average astrocyte process in human was almost twice as long as that in rodents in vitro (Zhang et al., 2016).

\section{(ii) Average branch numbers}

There is a difference in the average branch number in vitro for humans and rat: $8.5 \pm 1.1$ and $4.5 \pm 0.5$, respectively (Zhang et al., 
2016). This dataset was consistent with in vivo measurements (Oberheim et al., 2009).

\section{(iii) Glial to neuron ration}

A much higher ratio of glia to neurons has been estimated for the human cortex $(\sim 1.65: 1)$ than for rodent $(\sim 0.3: 1)$ (Nedergaard et al., 2003; Sherwood et al., 2006).

\section{(iv) Different classes of GFAP positive cells}

There are only two main types of astrocytes in mouse: fibrous astrocytes and protoplasmic astrocytes. In addition to these broad classes, two additional subtypes have been identified in human and other primates: interlaminar and varicose projection astrocytes (Colombo et al., 1995; Reisin and Colombo, 2004) (Table 1).

\section{(v) Gene expression pattern}

Only about $90 \%$ of the expressed genes in mouse and human astrocytes overlap (Sun et al., 2013), so there is the opportunity for unique sets of genes to up-regulate or down-regulate during astroglial development (Zhang et al., 2014, 2016). Differences have been found in the glutamate response (Zhang et al., 2016), and in the use of the TLR/IL-1R receptor and immune activation. For instance in mouse astrocytes, LPS induced mostly an A1 effective response, thereby producing abundant IL-1 protein. In the case of human astrocytes TLR4 receptor complex proteins and MD2 are expressed but not CD14 (Tarassishin et al., 2014). These results have critical implications for translational research of human CNS diseases.

\section{(vi) Supporting these observations}

Supporting these observations, essential differences in vivo between the two species include in vivo speed of calcium signaling, which is five times faster in humans (Sun et al., 2013), and the number of neuronal synapse networks, from $1 \times 10^{4}$ in mouse to up to $2 \times 10^{6}$ in humans (Oberheim et al., 2012). In vitro, adult human astrocytes responded differently to extracellular glutamate levels than those of adult mouse, which remained quiescent under the same conditions (Zhang et al., 2016).

Most strikingly, various drugs that showed promise in an animal model have failed in human trials (Cavanaugh et al., 2014; Cummings et al., 2014). Therefore advancement toward more human-relevant models is critical for the study of neurological disorders.

To overcome these obstacles, various laboratories have elaborated in vitro differentiation protocols to generate astrocytes from hPSCs. In the early 2000s, hESCs held great promise and were considered to be the most reliable source for the generation of human astrocytes and many other neuronal cell types. However, despite their potential benefits in disease modeling, the controversial and ethical issue of their derivation from early embryos remains. Takahashi and Yamanaka (2006) and Takahashi et al. (2007) published a groundbreaking method for generating iPSCs using four transcription factor (TF) genes (Oct4, Sox2, Klf4, and $c-M y c$ ) to reprogram somatic cells into PSCs. The discovery opened new possibilities in stem cell research providing new and ethically acceptable cell sources for PSC generation, and making it possible to derive stem cells directly from patients with different diseases, such as neurological disorders.

Since the advent of hiPSC technology, several groups have developed differentiation protocols to obtain human astrocytes from various pluripotent cell sources (hESCs and hiPSCs; see details in Table 3), very often adapted from protocols in published studies (Table 3). These protocols are continuously being upgraded to improve efficiency and functionality and differ significantly in multiple aspects (listed in Table 3), such as the cell seeding density at plating, the substrate, media composition, the timing and concentration of exogenous growth factors and morphogens, and the physical dimensions of the culture system (monolayer or embryoid bodies). These differences which might seem small at first glance make it very complicated to compare the outcome of the different methods. In this section, we aim to examine some of the most commonly used techniques in human astrocyte differentiation to provide a point of reference (also summarized in Table 3).

To establish a reproducible platform and to study astrocyteneuronal interaction, protocols first have to generate stable human NPC populations. During organismal development, the fate of the respective cell types is determined by the exact timing and concentration of growth factor/patterning signals at given locations. With knowledge of the patterning signals, in vitro astrocytogenesis of defined subpopulations could be achieved by exposing human PSC-derived primitive neuroepithelia to a set of diffusible signaling molecules, directing their differentiation into subpopulations that would arise in vivo in discrete regions along the neural tube. This process could generate functionally diversified classes of glial cells. A similar approach is commonly used for neurons (Kirkeby et al., 2012). For instance, FGF and RA determine rostro-caudal identity, whereas Wnts, BMPs, and Shh are required to specify NPCs along the dorso-ventral axis. We know that astroglial progenitors generated in the absence of mitogens carry a dorsal-anterior identity by expressing Otx2 but not Hoxb4 or Nkx2.1, while astroglial progenitors generated in the presence of RA express Hoxb4 but not Otx2 (Liu and Zhang, 2011). To mimic the in vivo mechanisms governing early neurogenesis (NPC formation), two major classes of protocols are utilized: an EB-based technique (with or without SMAD inhibition) and a monolayer-based dual SMAD inhibition method. Most protocols use aggregation of cells into EBs, and only a few rely on a monolayer-based adherent culture system (Shi et al., 2012; Roybon et al., 2013). The 3D aggregation system is thought to maintain the "stemness" of stem cells and to allow better cell-to-cell and cell-to-matrix interactions. Other vital considerations for improved neural cultures are media composition, exogenous growth factors or small molecules, and most importantly the timing of the procedure itself.

\section{The Neural Induction Protocol}

The neural induction protocol involves in dissociating PSCs and plating them on a feeder or feeder-free adherent culture system. 


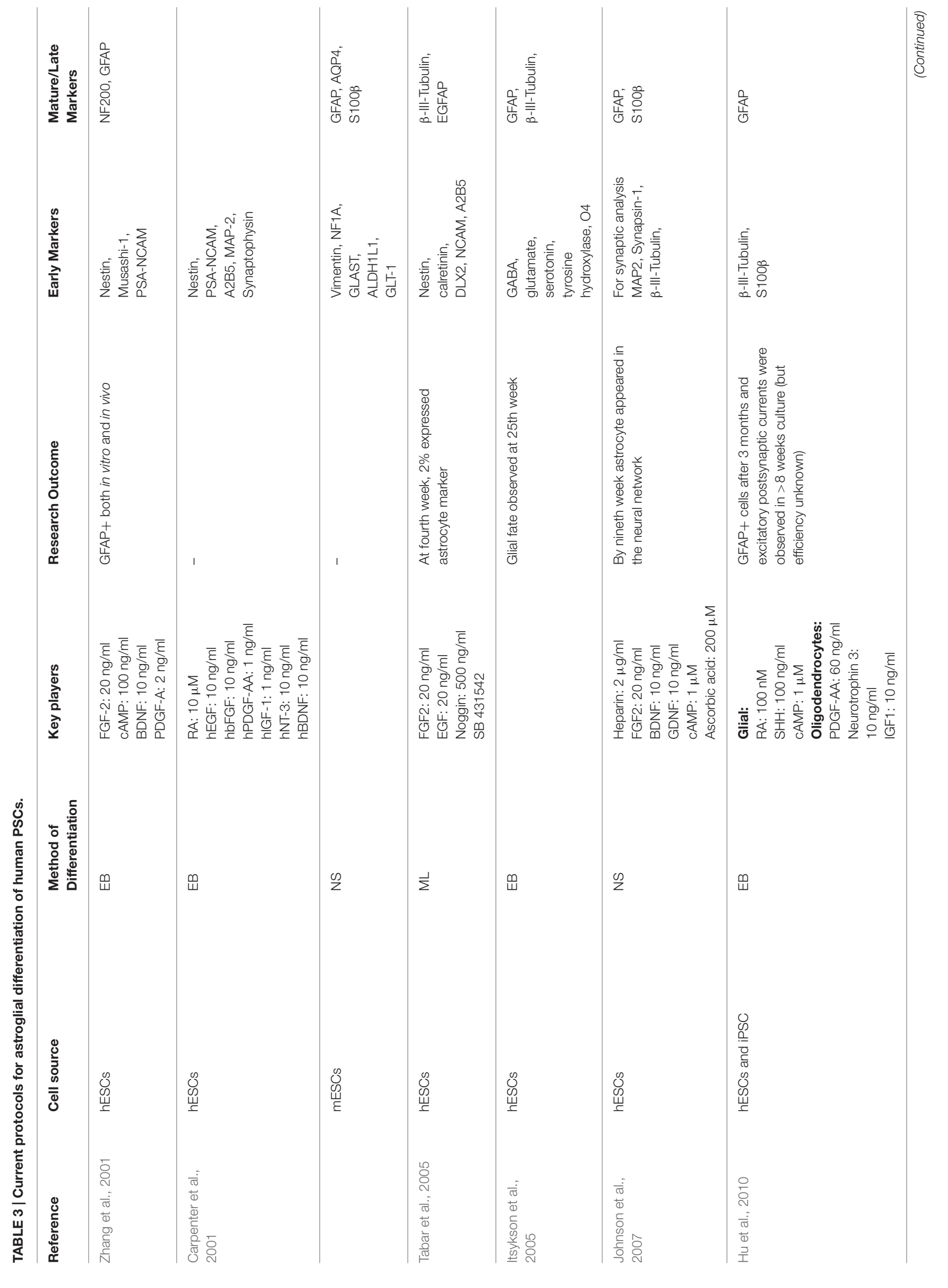




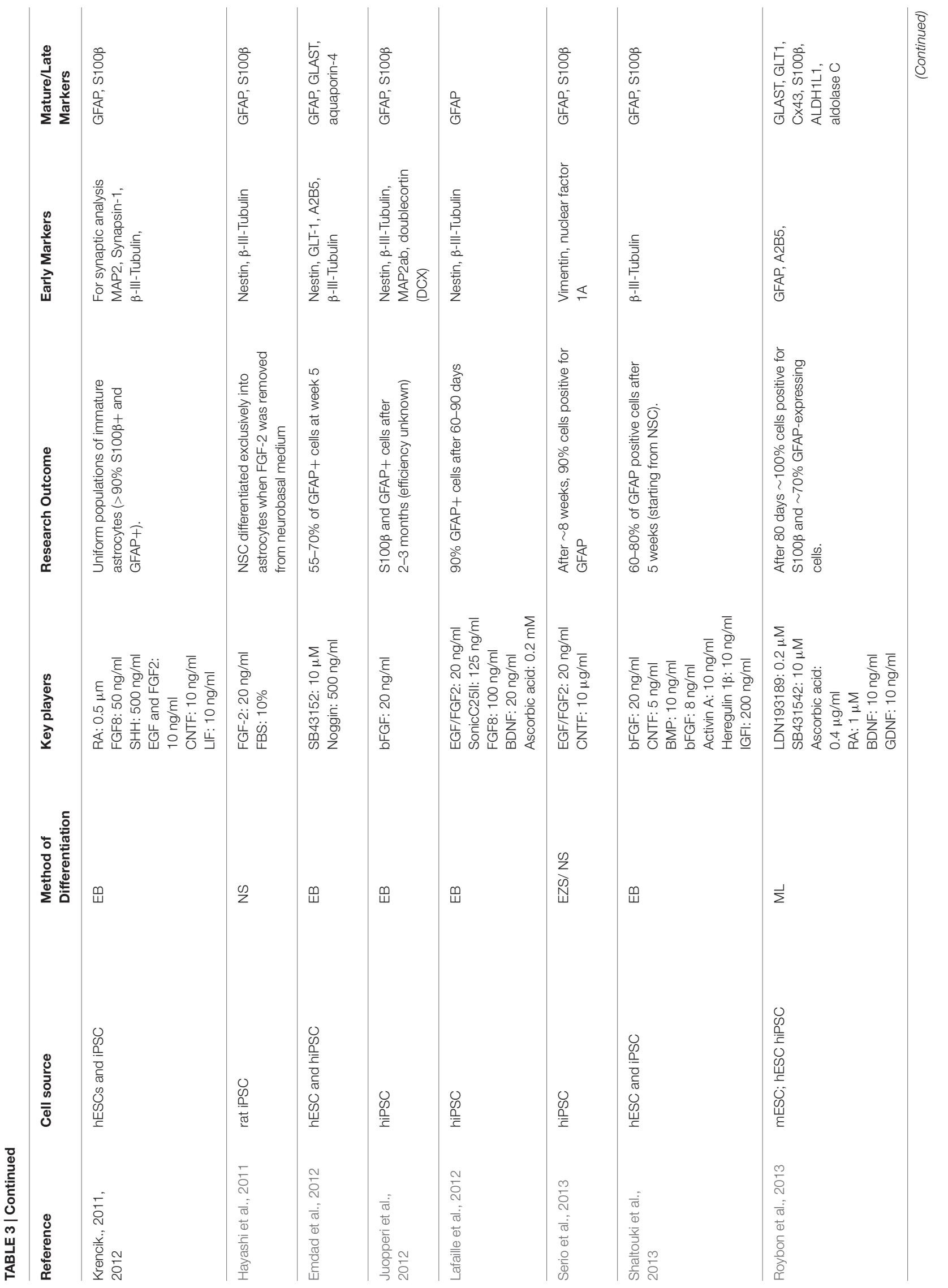




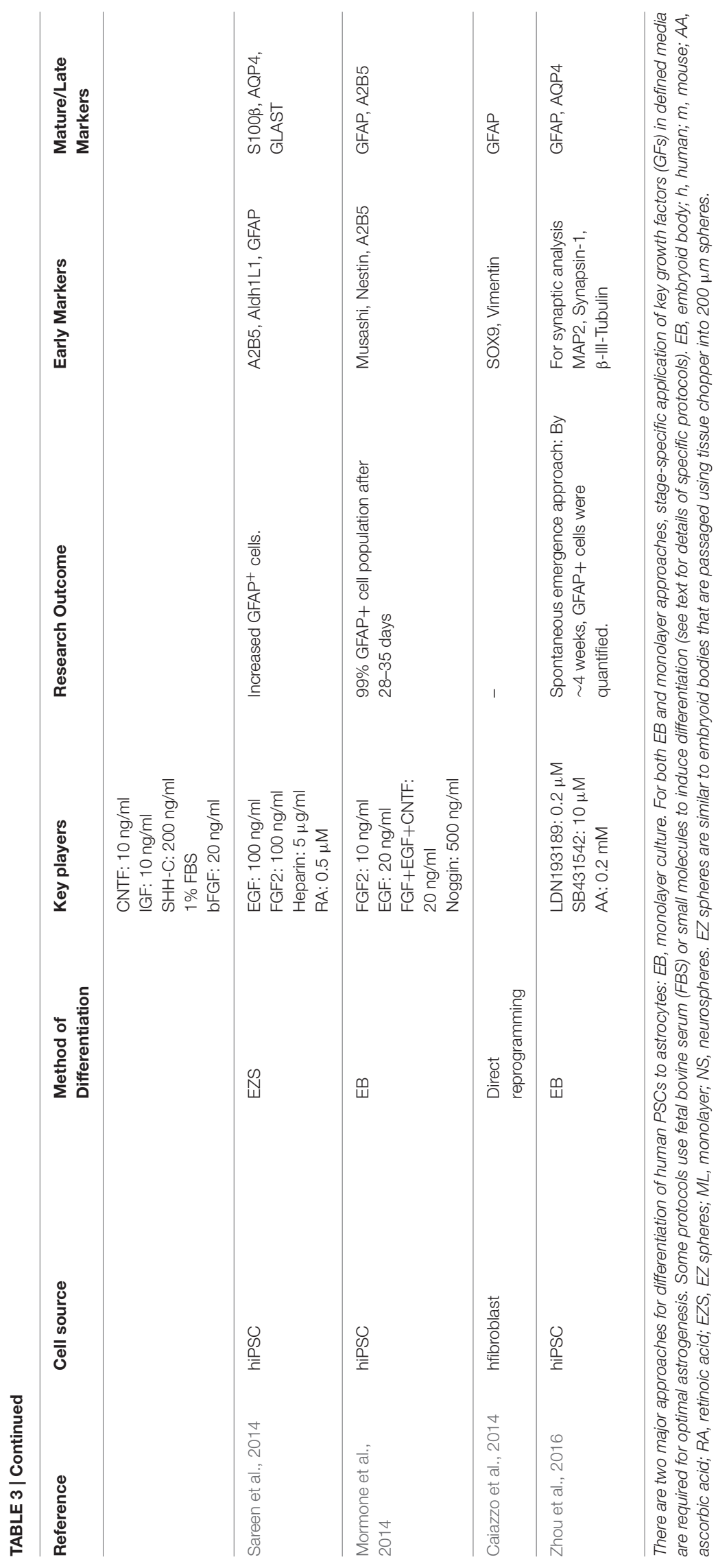


The media for neural induction usually consist of the neurobasal medium or DMEM/F12 medium, or combination of both. The cells are rapidly induced with antagonists, either LDN or noggin to inhibit the BMP pathway and SB431542 to inhibit the TGF- $B$ pathway, along with additional components to enhance neuronal precursors (Chambers et al., 2009) (Figure 2). The primitive neuroectodermal aggregates (3D system) or neuroepithelial sheets $(2 \mathrm{D}$ system) are then plated on the adherent substrate to promote the definitive neuroectoderm fate. Upon reaching the "end phase," NPCs are organized into polarized structures called neural rosettes. These neural rosettes are selected and cultured for several passages and then directed toward astroglial progenitors with different combinations of morphogens (CNTF, SHH, FGF, and RA) in defined culture medium. Numerous studies have utilized each of these methods, often with minor variations. However, it is not always clear why a particular method was chosen, and so it is very difficult to evaluate the exact effect of these small changes. In the next section, we have summarized the most efficient ways to generate human astrocytes from PSCderived NPCs through in vitro culture, and discuss the maturity of the derived astrocytes.

For neural differentiation of hESCs, most of the available methods are based on either the initial formation of embryoid bodies or on co-culture with stromal cells. First, we would like to compare the aggregate differentiation from monolayer differentiation.

\section{hESCs Studies on Embryoid Bodies}

Zhang et al. (2001) was the first to develop a novel technique to isolate and culture human astrocytes in serum-free conditions, thus recapitulating the resting, non-reactive state normally observed in healthy astrocytes in vivo, and went on to describe a differentiation technique for human ES cells that can be applied to model and study fetal and mature astrocytes in health and disease. In their first report (Zhang et al., 2001), differentiation was initiated by culturing the cells as $3 \mathrm{D}$ spheres in chemically defined medium containing FGF-2 for a short period. Subsequently, the EBs were grown in adherent culture to form neural rosettes. This unique cross-sectional arrangement of epithelial cells is now considered a hallmark of successful neural induction. By day 7, almost all EBs generated neural tube structures to produce neural progenitor cells and neural stem cells, and morphological analysis confirmed the expression of neural markers Nestin, Musashi-1 and neural cell adhesion molecule (NCAM). This group were the first to show the incorporated hESC-derived neural precursors in different brain regions upon transplantation into the neonatal mouse, with no teratoma formation. This remarkable development generated $\mathrm{GFAP}^{+}$astrocytes, oligodendrocytes both in vitro and in vivo.

In the same year, two other EB based differentiation studies were published (Carpenter et al., 2001; Reubinoff et al., 2001). Both studies also used hESCs in a 3D aggregate culture system in the presence of FGF-2 to induce neural differentiation. In one, EBs were differentiated into neuronal progenitors in the presence of RA along with selective morphogens (Carpenter et al., 2001) (detailed in Table 3), while in the other, differentiation occurred in the presence of just EGF and FGF-2 (Reubinoff et al., 2001). Therefore both the studies obtained populations with a wide panel of morphological characteristics, such as positive for Nestin, PS-NCAM, and A2B5. FACS analysis revealed $96 \%$ of the cells were positive for A2B5 (a marker for astroglial progenitors) (Carpenter et al., 2001).

\section{hESCs Studies on Monolayer}

Later, Tabar generated a neural progenitor population by inducing hESCs on stromal cells (MS5) in serum-free media (Tabar et al., 2005). To enhance the neural induction noggin was added to the N2 media. After a month neural precursors were isolated and maintained in N2 media containing FGF-2 and EGF. At this stage, the majority of cells (>90\%) were immunoreactive for neural precursor markers (Nestin, Musashi-1) and a glial progenitor marker (A2B5).

A better understanding of differentiation protocols has led us to conclude that the majority of hESC studies utilize the classic aggregation method to yield functional astrocytes in combination with different growth factor cocktails. Despite the potential benefits of hESC technology, the direct differentiation of hESCs toward astrocytes is rarely undertaken, for ethical reasons. Therefore we now compare some of the available protocols from human iPSCs technology (detailed in Table 3 and Figures 3A,B). For neural differentiation of hiPSCs, most methods available are either based on the initial formation of embryoid bodies or monolayer base methods.

\section{hiPSCs Studies on Embryoid Bodies}

Differentiation of hiPSC-derived NSC into astrocytes was first reported following the observation that astrocyte progenitor cells were $S 100 \beta$ positive after four weeks of differentiation and GFAP positive around the 12th week of differentiation (Hu et al., 2010). The study used a similar aggregated differentiation method to that of Zhang et al. (2001) to obtain neurons. To further enhance the glial differentiation the progenitors were expanded in N2B27 media containing additional factors, i.e., cAMP, T3, platelet-derived growth factor (PDGF), Insulin-like growth factors (IGFs), and neurotrophin-3 (NT-3), with the aim of increasing the formation of OLIG2 positive ventral progenitors and reducing the formation of $\mathrm{HB}^{+}$postmitotic motoneurons (Hu et al., 2010).

In the subsequent years, additional studies have described the generation of astroglial cells from human PSCs, including a landmark study that generated functional astrocytes from iPSC that were indistinguishable from hESC-derived astrocytes (Emdad et al., 2012). The study involved culturing EBs on low attachment plates in neurobasal media for 2 weeks to develop columnar epithelium within the formed EBs. And also investigates the astrocyte differentiation potential with three different conditions: (1) CT-1 alone, (2) CT-1 in combination with CNTF, and (3) recombinant Jagged-1 (JAG1-Fc) in conjunction with CNTF. The results have showed high number of hiPSC-derived NE cells after sequential treatment with FGF- $2+$ CNTF followed by CNTF alone. However, no incremental effect 


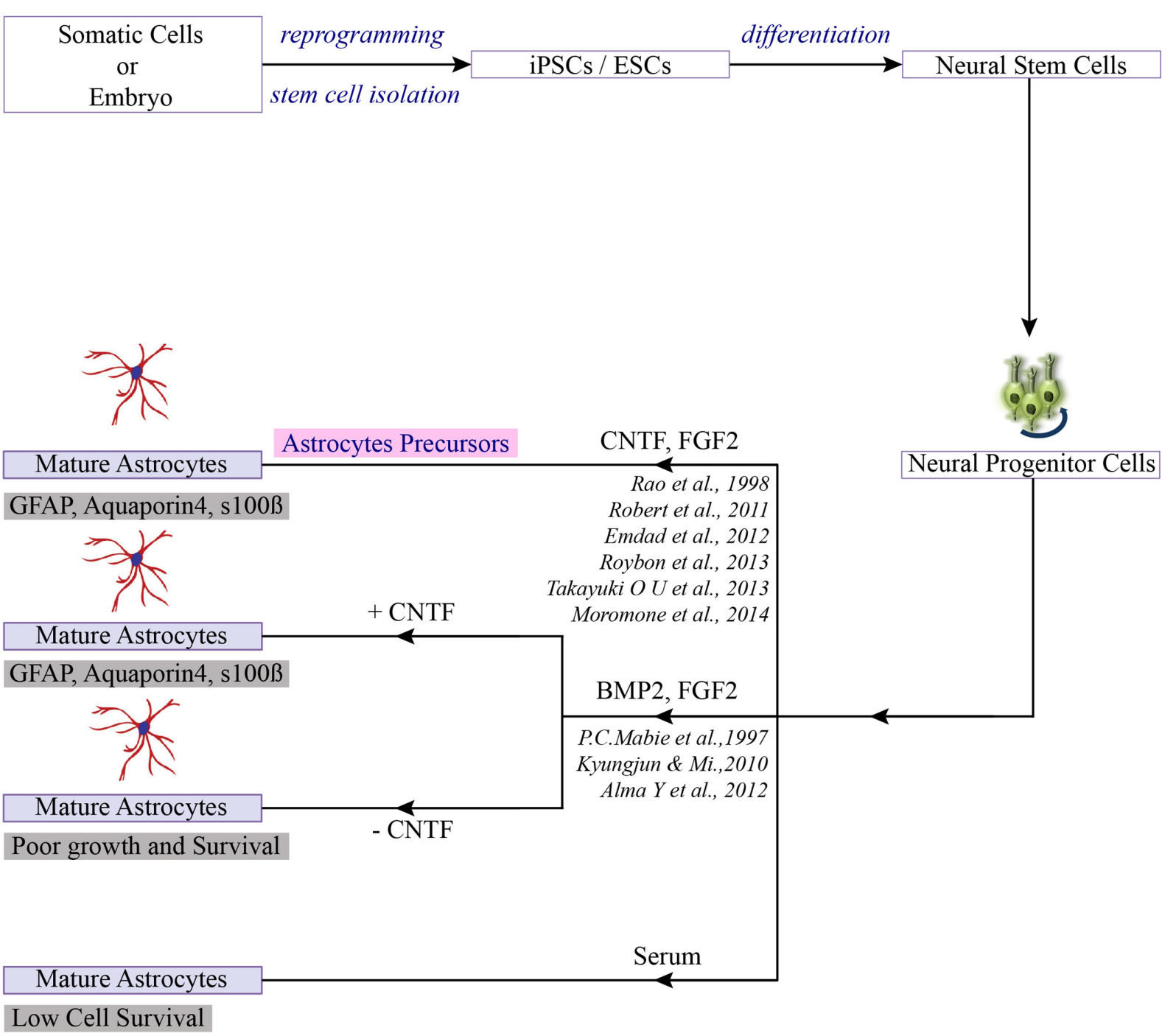

FIGURE 2 | Differentiation of PSCs toward astrocytes. Once the neuro-progenitors are produced from pluripotent stem cells, addition of selection factors can lead to the generation of mature astrocytes or astrocytes precursor (Jha et al., 2015).

on astrocytic differentiation was observed when CT-1, Notch activator JAG1-Fc was used.

Later, Lafaille described the efficient generation of astroglial cells within 10 weeks (Lafaille et al., 2012), adapting previously described protocols to enhance neural differentiation (Zhang et al., 2001; Elkabetz et al., 2008). The derived neural crest stem cells (NCSc) and NPCs from hPSCs were expanded in defined conditioned medium supplemented with EGF and FGF-2 for 8 weeks, followed by 5\% FBS treatment for 20 days, leading to $90 \% \mathrm{GFAP}^{+}$cells.

The next study went on to show the efficient generation of astroglial cells within the short time frame of 6 weeks from hPSC-derived NSCs, using a defined medium system (Shaltouki et al., 2013). As might be expected, the differentiation protocol was EB based, with the colonies cultured in suspension for 8 days before surface attachment. Formed neural rosettes were manually isolated and replated to acquire a homogenous population of NSCs, that was then stimulated with neurotrophic factor (CNTF) and proteins (BMP, FGF-2) to significantly increase the proportion of GFAP positive cells. These differentiated astrocytes were then plated on neurons to quantify synapse formation. Interestingly, the number of synaptic puncta remained significantly higher in the presence of astrocytes, indicating that these in vitro astrocytes displayed similar functional characteristics and morphological patterns to primary astrocytes.

Other studies have added further evidence for the generation of astroglial cells. Sareen et al. (2014) generated so-called "EZ spheres" from hiPSCs that could be differentiated into neural progenitor cells with an astroglial predisposition. The "EZ sphere" is a free-floating cell aggregate containing 
pre-rosette stem cells, that is generated directly from PSCs. The EZ spheres were caudalized using all-trans-RA in neurobasal medium and maintained their proliferative capacity for 30 passages. For astroglial differentiation, they were dissociated and plated as single cells (Sareen et al., 2014). Like Sareen, the study by Serio et al. (2013) opted for EZ sphere formation; neurospheres were mechanically chopped at the beginning of the enrichment phase and cultured in neurobasal medium for 2-4 weeks, before being dissociated to form NPCs. Astrocyte populations were obtained by differentiating NPCs in CNTF (Serio et al., 2013). The resulting population robustly expressed both developmental

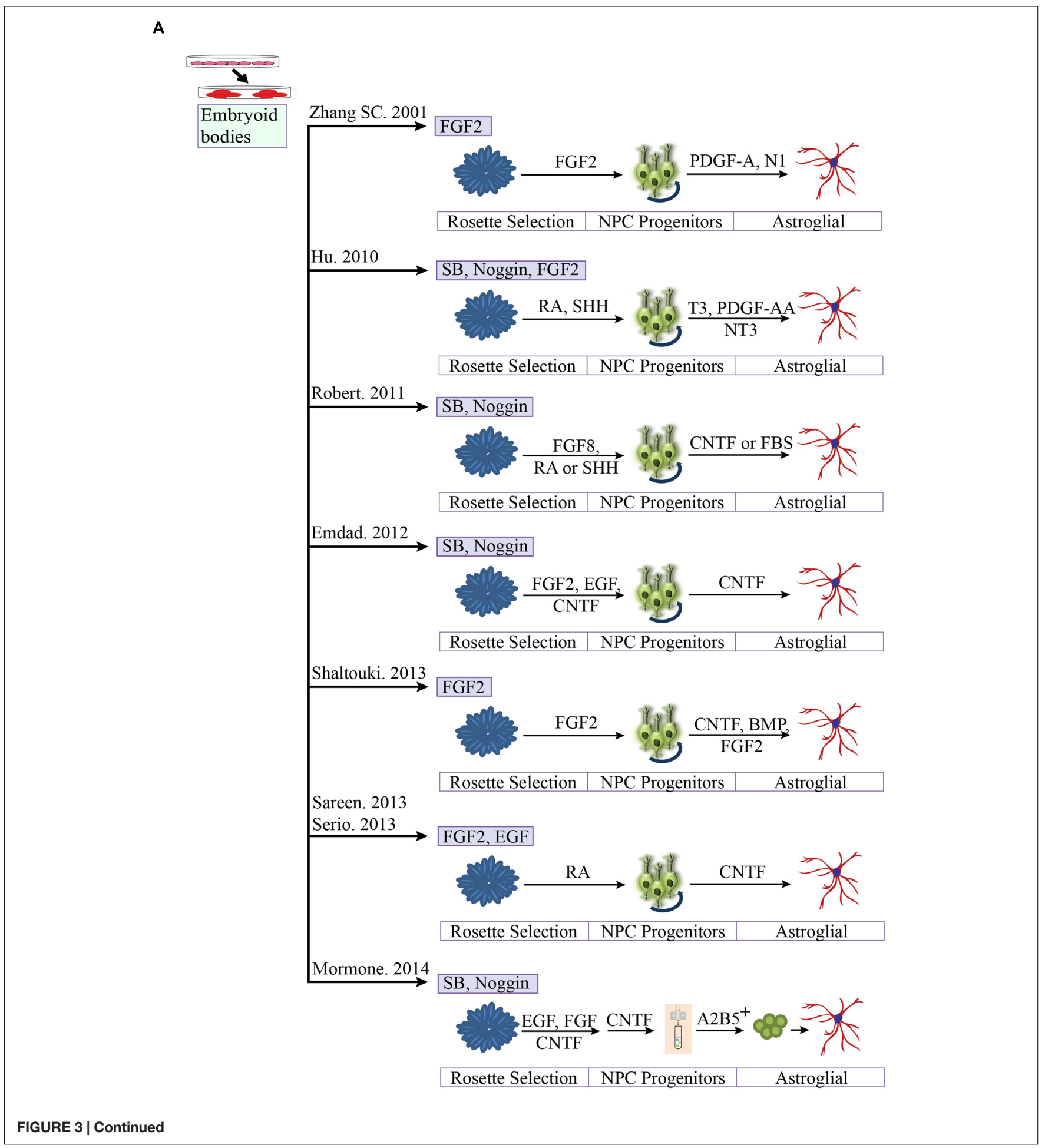


B

C
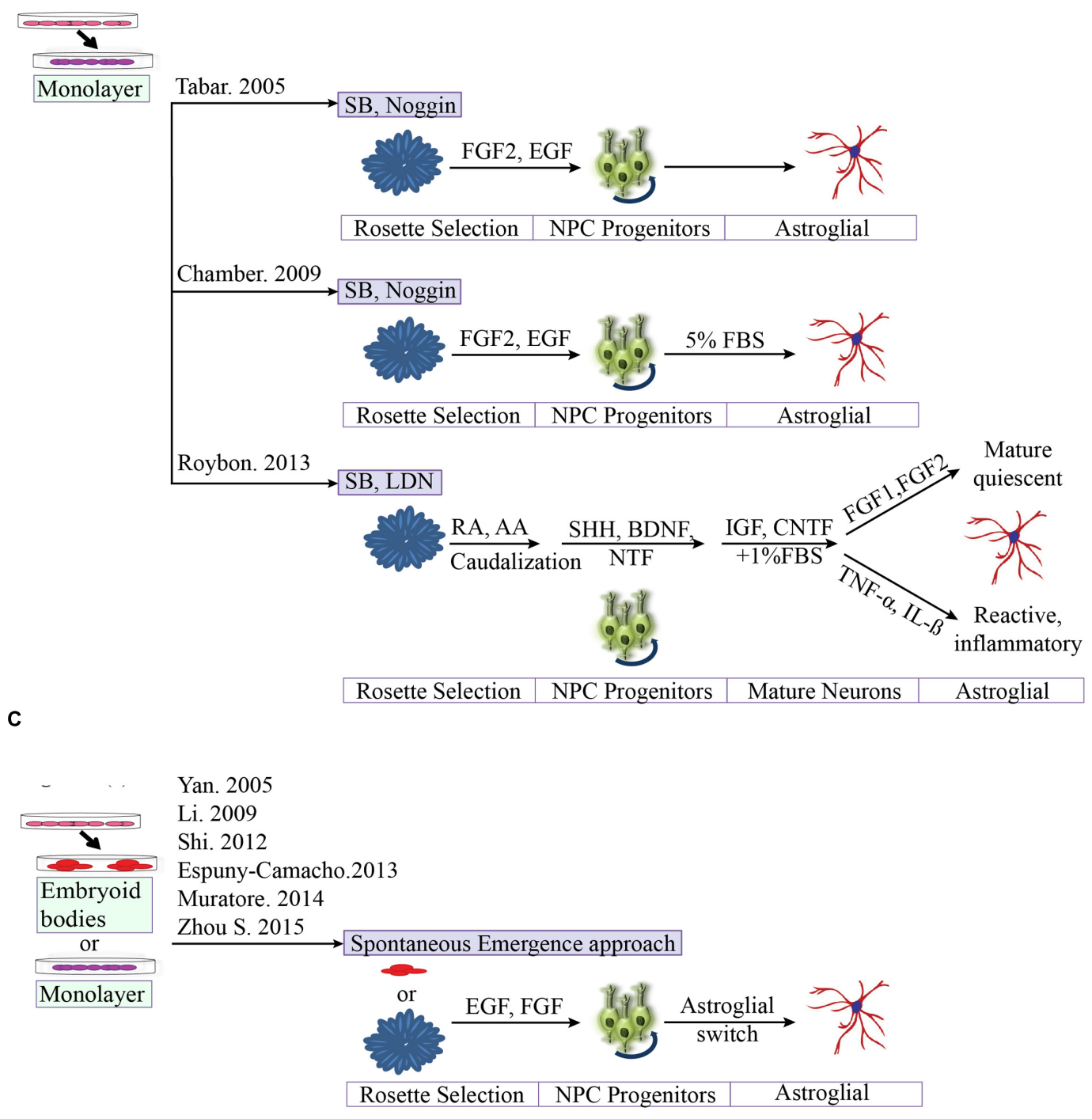

FIGURE 3 | Comparison of different protocols for deriving astroglial cells from human pluripotent stem cells. (A) Generation of astroglial cells from 3D aggregates or neurosphere through neural progenitor's cell stage. iPSCs are dissociated at day 1 and cultured as aggregates in suspension. Aggregates are replated onto culture dish to form primitive neuroepithelial structures. Upon reaching definitive NE structures are manually isolated and replated for progenitors. (B) Methods based on neuronal rosette selection. Rosette structures are mechanically harvested and replated in appropriate growth factors for specific progenitors (C) Spontaneous emergence approach. Endogenous astrocytes gradually emerge over time, say after 40 days.

(Nestin, vimentin, GFAP) and mature astrocyte markers (S100ß).

The most striking feature of these studies is the formation of the EZ sphere $(\sim 200 \mu \mathrm{m})$ which represents the primitive type of neural stem cells at a stage before early neural tube formation. While various protocols exist for the generation of PSC-derived neural progenitor cells, including the complex four stage systems involving RA-mediated induction, adherent culture, and neural rosette isolation, all these methods can be laborious when compared to EZ sphere formation.

Mormone and co-workers then generated iPSC-derived astrocytes with characteristics similar to those differentiated from hESCs by culturing clusters of cells in low attachment plates in the presence of neurobasal media supplemented with different factors such as FGF-2, EGF, and CNTF, at various time points. Cells were then subjected to immunopurification via magnetic cell sorting for the "positive selection of A2B5 cells," before being plated in neurobasal medium containing CNTF for an additional 2 weeks. A2B5 is mostly expressed in embryonic neural tissue and is therefore considered to be a marker for immature glial-committed precursors that give rise to glial types such as astrocytes and oligodendrocytes. The authors reported 99\% GFAP-positive cells at fourth week of differentiation with the absence of teratoma 
formation in long-term experiments (Mormone et al., 2014).

\section{hiPSCs Studies on Monolayer Base Methods}

Roybon et al. (2013) generated two subpopulations of human astrocytes in vitro: the first subpopulation was generated from stem cells (derived from human PSCs) and was capable of an immunological response similar to human primary astrocytes, while the second subpopulation contained mature, quiescent astrocytes (Roybon et al., 2013). When co-cultured with MNs, these astrocytes also enhanced neuronal survival and neurite outgrowth. Strikingly, they also found that the addition of either FGF1 or FGF2 was sufficient to promote transitions, maturation/quiescence without triggering inflammatory responses (TNF $\alpha$ or IL-1). It should be noted that although the majority of the existing protocols administer FGF2 into the media (Table 3), the exact role of FGF2 in in vitro astrocyte differentiation is uncertain. There is evidence to suggest that FGF-2 has an additional feature in gliogenesis beyond driving the propagation of neural stem cells both in vitro and in vivo. The possible mechanisms of action are: (i) FGF2 in combination with a second factor (e.g., CNTF or BMP2), but not FGF2 alone, may trigger astrocytogenesis; (ii) FGF2 may trigger early commitment of NSC to astrocytes, but is not sufficient to transform the cells to astrocytes; or (iii) astrocytogenesis may be a stressful process for NSC, and the presence of FGF2 keeps the cells alive and proliferative, while other factors could decide the way of the differentiation (Song and Ghosh, 2004; Kang and Song, 2010).

\section{Emerging Trends in Astroglial Differentiation}

The strategy to recapitulate neurogenesis and astrogenesis during early development has gained increased attention in modern science. The generation of human RG-type cells from PSCs in a chemically defined medium without adding morphogens validates that cultured hRGs maintain a cell-intrinsic clock that regulates the progressive generation of stage-specific neuronal and glial subtypes (Duan et al., 2015). One step further, a 3D culture approach for generating human cortical spheroids (hCSs), a laminated cerebral cortex-like structure, from PSCs initially showed only a few GFAP positive cells after 35 days of differentiation. This later increased to $8 \%$ on the 76 th day and almost 20\% after 180th day (Paşca et al., 2015). Finally, Caiazzo et al. (2014) demonstrated that the direct conversion of human fibroblast by overexpressing a defined group of TFs (NFIA, NFIB, and SOX9) led to the rapid single-step generation of human induced astrocytes. The study makes use of inducible TFs which are selectively expressed in astrocytes. Unlike any other studies, this research indicated a direct reprogramming process with no intermediate states resembling either ESCs or NSCs. To our knowledge, this is the first report that shows astrocyte-like cells derived from fibroblasts by entirely skipping the iPSC generation. The expression of astrocyte marker proteins (S100 $\beta$ and GFAP) was detected in induced astrocytes. However, further experiments are required to prove the functional similarity to human astrocytes (Caiazzo et al., 2014). Therefore, regardless of approach, it is a matter of generating authentic RG-like NSC/NPCs which can be further differentiated into astroglial-like cells. To obtain a more gliogenic NSCs/NPC type, it is, therefore, necessary to induce the differentiation with RA and subsequently immune-isolate for CD133-positive cells. This principle was shown for human cells (Gorris et al., 2015) and murine cells (Kleiderman et al., 2016).

\section{Astrocyte Maturation Studies}

Astrocyte maturation occurs through a series of complex events, which remain poorly understood. Some reports have suggested that IL-6 family cytokines (such as LIF, CNTF) (Bonni et al., 1997) or BMPs (BMP2, BMP4) (Gross et al., 1996) have a comparable potential to induce differentiation of astrocytes from neural progenitor cells. Some published protocols have achieved astroglial maturation by culturing cells in the presence of different combinations of FGF-2, EGF, and CNTF for changing time periods (Emdad et al., 2012). Others have achieved astrocyte maturation by any of the following combinations: (i) maintenance media along with $10 \%$ fetal bovine serum (FBS) (Palm et al., 2015); (ii) maintenance media in the presence of BMP-4 (preferably for rodents); (iii) maintenance media with CNTF; or (iv) maintenance medium with bFGF, NT3 and/or PDGF-AA (Juopperi et al., 2012; Haas and Fischer, 2013; Tanga et al., 2013). These methods can generate robust populations of functionally diversified astrocytes with high efficiency, based on staining for $\beta$-IIItubulin, GFAP, and AQP4, but their functional maturation and efficacy varies considerably among different studies and cell lines.

\section{Spontaneous Emergence Approach}

Astrocytes can also emerge spontaneously in neuronal cultures by the "spontaneous emergence approach" (Figure 3C). For example, human iPSC-derived NPCs have been differentiated toward various neuronal lineages such as cortical neurons (Li et al., 2009), midbrain dopaminergic neurons (Yan et al., 2005) and spinal MNs, where astrocytes and oligodendrocytes frequently appear as side products in these preparations, however, the efficiency is low and not reliable. A numbers of protocols have been derived from this approach. A recent study showed the emergence of endogenous astrocytes from neuronal cultures via increased expression of the glial fibrillary acidic protein (GFAP), a marker of astrocytes, at day 100, with confirmation through the NanoString platform (Muratore et al., 2014). Other groups have also confirmed the emergence of astrocytes with long-term differentiation of hiPSCs-derived neural progenitors (Shi et al., 2012; Espuny-Camacho et al., 2013). A new 3D based protocol published by our group was able to generate neuronal cultures enriched in $\mathrm{GFAP}^{+}$and Aquaporin $-4^{+}$astrocytes (Zhou et al., 2016). However, all of these protocols are complex, time-consuming, difficult to expand 
and have fewer functional properties than the in vivo models or directed approach.

\section{Toward a Standardization of Protocols}

The generation of astrocytes from human PSC has reached a state where the cells can be considered for clinical applications and various research questions. It is now important to take stock, to identify remaining research needs and to work toward protocols that provide standardized sets of cells. Concerning the latter point, it would be important to develop consensus criteria of how a 'high quality astrocyte population' should be defined. Such criteria will need to account for different applications of the astrocytes. For instance, the requirements for cells intended for transplantation will be different from those required for pre-clinical target discovery, or disease modeling, or construction of in vitro 3D tissues. However, in all instances, the cell population will need to be characterized for: (i) purity according to positive markers and also for negative markers; (ii) for maturity/region-selectivity, e.g., by using markers, secretion of growth factors and/or gene expression profiling; (iii) function, e.g., by functional assays like looking at glutamine synthesis or inflammatory activation or by quantifying the support of neuronal growth and synapse formation; as well as (iv) cell cycle state - most of the cells should be non-proliferative. To our knowledge, none of the available protocols has been fully characterized for all this information, and each available protocol still has drawbacks: (i) some of the protocols do not provide sufficient detail for reproduction; (ii) astrocyte purity and maturity is not comparable to that obtained with primary isolated astrocytes; (iii) there are technical issues that prohibit widespread use, even though the protocol may be suitable (e.g., long-term induction process that might result in $>120$ days protocol to generate astrocytes); and (iv) the emerging astrocytes are often poorly characterized (e.g., are only stained for classic markers such as GFAP and S100ß), but hardly for maturity markers, regional identity, negative markers and additional astrocyte functional characterization. Some astrocytes have been generated from PSC in the presence of patterning molecules known to shape the nervous system. In this way either spinal cord phenotypes (Krencik et al., 2011; Roybon et al., 2013; Serio et al., 2013; Sareen et al., 2014) or astrocytes with forebrain identity have been generated (Shaltouki et al., 2013). However, most studies have not explored the region-specific phenotype of the astrocytes generated in vitro.

For this reason, there is no protocol at present that has become a gold standard, and there is still a need both for further protocol optimization and for better characterization and standardization of the resultant cell types.

\section{ASTROCYTES IN NEUROLOGICAL DISEASES}

Since the importance of astrocytes for functional neuronal networks has long been underestimated, it is not surprising that their central role in many neurological disorders was equally neglected. Experiments on mouse models of human neurological diseases including diverse neurodegenerative diseases (e.g., AD, ALS, Parkinson's disease, and spinocerebellar ataxia) and neurodevelopmental disorders (e.g., Alexander's disease, Autism spectrum disorders, Epilepsy and Rhett syndrome) have led to advances in understanding astrocyte biology (Table 4, for the overview of pathological affected gene defects). In most of the diseases, however, it remains unclear whether the pathologic changes are caused by astrocytes or rather a consequence of preceding events.

It is worthwhile to mention the success of iPSC technology in regards to neural-glial disease modeling including Parkinson disease (Rhee et al., 2011; SánchezDanés et al., 2012), demyelination (Tokumoto et al., 2010; Czepiel et al., 2011; Pouya et al., 2011), retinal regeneration (Parameswaran et al., 2010; Tucker et al., 2011), nerve degeneration (Wang A. et al., 2011) and various others (Saporta et al., 2011). Recent studies by Chen et al. (2014) shed light on understanding the disease phenotypes of DS using an iPSC tool. This study tested minocycline (an FDA approved drug) to correct the pathological phenotypes of DS astroglia. Notably their results demonstrated higher levels of GFAP/S100 $\beta$ expression as compared to control astroglia. Therefore iPSCs technologies are now considered to be a valuable platform to model diseases and improve our understanding of pathomechanisms. Furthermore, they can be employed for drug screening and testing. In the following section, we would like to discuss some of the diseases that could see, or already have seen, benefits from this technology.

\section{Alexander Disease (AxD)}

Alexander disease is a progressive astrogliopathy caused by a dominant gain-of-function mutation in the GFAP gene that maps to chromosome 17q21 (Brenner et al., 2009). It is a primary disease of astrocytes that affects neural development and causes mental retardation, seizures, and megaencephaly in early childhood. There are three agedependent clinical subtypes of $\mathrm{AxD}$ : infantile, juvenile and adult-onset. Infantile $\mathrm{AxD}$ is very aggressive and is characterized by seizures, and bulbar dysfunction with low life expectancy. Juvenile $\mathrm{AxD}$ is characterized by hyperreflexia and bulbar symptoms affecting children between 2 and 14 years of age, and is milder than the infantile form. Adult AxD which affects the late adolescence and beyond, has similar characteristics to the juvenile form (Prust et al., 2011).

In this disease, there is no known metabolic abnormality. Pathophysiology reveals abundant astrocytic accumulations of eosinophilic cytoplasmic inclusions, known as RF, one of the hallmarks of AxD (Molofsk et al., 2012). RF are protein aggregates composed of Vimentin, GFAP and small heat shock proteins that are present in the cytoplasm of astrocytes. The clinical signs of AxD are likely due to astrocyte dysfunction rather than astrocyte loss (Messing and Goldman, 2003). In vitro studies have provided additional clues that astrocytemediated effects in $\mathrm{AxD}$ are due to oxidative stress and 
TABLE 4 | Summary of the astrocyte-affected diseases.

\begin{tabular}{|c|c|c|c|}
\hline $\begin{array}{l}\text { Astrocyte } \\
\text { affected } \\
\text { disease }\end{array}$ & $\begin{array}{l}\text { Astrocyte associated defects or gene } \\
\text { defects }\end{array}$ & $\begin{array}{l}\text { Astrocytes mediated pathological or } \\
\text { neurological features }\end{array}$ & Reference \\
\hline $\begin{array}{l}\text { Hepatic } \\
\text { encephalopathy }\end{array}$ & $\begin{array}{l}\text { Astrocyte swelling and neurotransmitter } \\
\text { receptor alternation }\end{array}$ & Cytotoxic brain oedema & $\begin{array}{l}\text { Felipo and Butterworth, 2002; } \\
\text { Butterworth, 2010; } \\
\text { Chen et al., 2012; } \\
\text { Takayama, } 2015\end{array}$ \\
\hline $\begin{array}{l}\text { Neuromyelitis } \\
\text { optica (NMO) }\end{array}$ & $\begin{array}{l}\text { Auto-antibody; loss of aquaporin } 4^{+} \text {and } \\
\mathrm{GFAP}^{+} \text {astrocytes }\end{array}$ & $\begin{array}{l}\text { Inflammation, demyelination, astrocyte loss and } \\
\text { nerve injury }\end{array}$ & $\begin{array}{l}\text { Lennon et al., 2004; } \\
\text { Wingerchuk et al., 2007; } \\
\text { Marignier et al., 2010; } \\
\text { Tradtrantip et al., } 2012\end{array}$ \\
\hline Balo's disease & Loss of aquaporin $4^{+}$and $\mathrm{CX} 43$ & Demyelination and astrocyte hypertrophy & $\begin{array}{l}\text { Tokumoto et al., 2010; } \\
\text { Czepiel et al., 2011; } \\
\text { Pouya et al., 2011; } \\
\text { Linnoila and Chitnis, } 2014\end{array}$ \\
\hline $\begin{array}{l}\text { Wernicke's } \\
\text { encephalopathy }\end{array}$ & $\begin{array}{l}\text { Loss of EAAT1 (GALST) and EAAT2 (GLT-1); } \\
\text { decreased level of aquaporin } 4\end{array}$ & Loss of neurons, oedema, gliosis & $\begin{array}{l}\text { Sechi and Serra, 2007; } \\
\text { Lough, } 2012\end{array}$ \\
\hline $\begin{array}{l}\text { Alexander } \\
\text { disease }(A x D)\end{array}$ & Mutation in GFAP protein & $\begin{array}{l}\text { Accumulations of eosinophilic cytoplasmic } \\
\text { inclusions, known as RF }\end{array}$ & $\begin{array}{l}\text { Prust et al., 2011; } \\
\text { Wang L. et al., 2011; } \\
\text { Molofsk et al., 2012; } \\
\text { Lanciotti et al., 2013 }\end{array}$ \\
\hline $\begin{array}{l}\text { Alzheimer } \\
\text { disease (AD) }\end{array}$ & Synaptic loss and neuronal death & $\begin{array}{l}\text { Deposition of extracellular SPs and } \\
\text { neurofibrillary tangles }\end{array}$ & $\begin{array}{l}\text { Wyss-Coray et al., 2003; } \\
\text { Koistinaho et al., 2004; } \\
\text { Castellano et al., 2011; } \\
\text { Li et al., 2011; } \\
\text { Sidoryk-Wegrzynowicz et al., 2011; } \\
\text { Israel et al., 2012; } \\
\text { Kondo et al., } 2013\end{array}$ \\
\hline $\begin{array}{l}\text { Vanishing white } \\
\text { matter (WWM) }\end{array}$ & $\begin{array}{l}\text { Autosomal recessive neurological disease, } \\
\text { Mutation in elF2B, elF2B is a guanine } \\
\text { nucleotide-exchange factor for elF2 }\end{array}$ & $\begin{array}{l}\text { Gray matter remains normal, whereas white } \\
\text { matter changes texture. Abnormally shaped } \\
\text { astrocytes with febrile infections }\end{array}$ & $\begin{array}{l}\text { La Piana et al., 2012; } \\
\text { Elroy-Stein and Schiffmann, } 2014\end{array}$ \\
\hline $\begin{array}{l}\text { Megalencephalic } \\
\text { leukodystrophy }\end{array}$ & $\begin{array}{l}\text { Is an early-onset macrocephaly, } \\
\text { Degeneration of motor functions }\end{array}$ & $\begin{array}{l}\text { Intramyelinic vacuole formation, alterations of } \\
\text { the blood-brain barrier structure and astroglial } \\
\text { activation }\end{array}$ & $\begin{array}{l}\text { Anand et al., 2007; } \\
\text { Brignone et al., } 2014\end{array}$ \\
\hline
\end{tabular}

Aldh1L1, aldehyde dehydrogenase 1.

reduction in the GLT-1. Therefore these observations suggest a possible pathogenic mechanism underlying neuronal loss in $\mathrm{AxD}$. Other possible astrocytic failures that contribute to myelin degeneration in $\mathrm{AxD}$ are $\mathrm{K}^{+}$buffering, and $\mathrm{Na}^{+} / \mathrm{K}^{+}$ATPase activity (Lanciotti et al., 2013). To address the clinical importance of astrocyte dysfunction in $\mathrm{AxD}$, there is a critical need for the new model system, as so far only a Drosophila model exists (Wang L. et al., 2011).

\section{Amyotrophic Lateral Sclerosis (ALS)}

Amyotrophic lateral sclerosis is an adult-onset neurodegenerative disease manifested by degeneration of MNs in the motor cortex, brain stem, and spinal cord, resulting in muscle paralysis and ultimately motor neuronal death (Rowland and Shneider, 2001; Kiernan et al., 2011). Most of the cases of ALS are sporadic with unknown genetic mutation; only about $5-10 \%$ of ALS cases are caused by known genetic mutations, among which $20 \%$ are caused by mutations in the copper/zinc SOD-1 gene. Mutations of SOD1 were identified through an autosomal-dormant inheritance pattern (Rosen et al., 1993). Gurney et al. (1994) were the first to recapitulate the hallmarks of ALS using a transgenic mouse model (SOD1 G93A mutant mouse) that expresses human copies of SOD1 enzyme with glycine-alanine substitution at the 93rd codon of the coding sequence (Gurney et al., 1994; Rothstein et al., 1995). Over the years, a variation of SOD1 mutants have been subsequently developed as G37R, G85R, and G86R transgenic; although these models differ in protein content, they develop the same $\mathrm{MN}$ degeneration that is characteristic of ALS (Turner and Talbot, 2008). In the past two decades exhaustive efforts have been made to significantly improve the understanding of ALS disease, and at least eight variations of the disease have now been identified (ALS1-ALS8) indicating the complexity of $\mathrm{MN}$ degeneration. At present, the G37R, G85R, and G86R transgenic models are considered to be the most reliable and accurate animal models of ALS, where they have been extensively 
used in understanding the mutation of SOD1 that causes cell death.

Despite the improvement in understanding ALS pathogenesis from the use of transgenic models, there is still a lack of understanding of, or effective treatment for, ALS disease. However, modeling ALS using rodents with an ALS-carrying mutation only represents a subset of the disease, and since ALS is a slowly progressive neurodegenerative disease, modeling ALS using transgenic animal models requires months of study which results in increased cost. To overcome these limitations, the research community has shown keen interest in using iPSC models for ALS disorders. Recent studies have emphasized the involvement of astrocyte dysfunction in the pathogenesis of ALS. One of the standard features of both familial and sporadic ALS is the loss of astrocyte GLT-1, (EAAT2) from the synaptic cleft; regulating synaptic transmission and preventing glutamate excitotoxicity. Supporting the hypothesis of MN degeneration caused by excitotoxicity (Barbeito et al., 2004). Multiple groups have performed ALS iPSC disease modeling from patients with familial and sporadic ALS (Chestkov et al., 2014; Liu et al., 2014). Work by Krencik et al. (2011) in was significant in broadening the tools for ALS research by demonstrating that astrocytes could be generated from human ESCs. When astrocytes generated from hPSCs were transplanted into the lateral ventricles of neonatal mice, they observed that the regional identity specified in vitro was retained. Strikingly, the transplanted cells also developed end-feet suggesting that these cells were able to contribute in the formation of the BBB (Krencik and Ullian, 2013). Recently, astrocytes directly reprogrammed from ALS patients carrying TARDBP mutations showed abnormalities typical of a TDP-43 proteinopathy, including its cytoplasmic mislocalisation. Imaging of mutant astrocytes revealed that TDP- 43 mislocalisation decreased cell survival, suggesting that mutant TDP-43 is responsible for astrocyte pathology. Apparently, mutant astrocytes were not toxic when co-cultured with either control or mutant TARDBP MNs (Serio et al., 2013). In two other reports hiPSCs were utilized to study SOD1 mutation in MNs. Kiskinis et al. (2014) used high-resolution RNA sequencing technologies to identify the transcriptional and functional changes induced by the SOD1A4V dominant mutation in human MNs and found that the expression of mitochondrialrelated (Jiang et al., 2013) and ER-stress-mediated genes were significantly reduced. While the other study by Chen et al. (2014) discovered an autonomous behavior of mutated SOD1 in MNs caused by destabilization of neurofilament subunits.

\section{Hepatic Encephalopathy (HE)}

Hepatic Encephalopathy is another example of how astrocyte dysfunction can cause a neurological disease. HE accompanies both acute and chronic liver failure and is characterized by the accumulation of ammonia in the brain that is detoxified by astrocytic GS, resulting in increased osmotic forces, which then leads to cytotoxic oedema and astrocyte swelling. It seems that altered neurotransmission is responsible for the excessive ammonia levels that lead to the cognitive and motor impairments seen in patients with HE. In the brain of $\mathrm{HE}$ patients, neurons appear to be morphologically normal, but astrocytes show signs of Alzheimer type II degeneration, i.e., nuclear enlargement, prominent nuclei, chromatin changes, and neurotransmitter receptor alteration (Felipo and Butterworth, 2002; Butterworth, 2010). There have been some animal studies evaluating BBB integrity in acute liver failure, but there has been less research on this subject conducted on humans. To our knowledge, Chen et al. (2012) evaluated the hepatoprotective property of 3 -genes iPSC transplantation in a carbon tetrachloride (CCl4)-induced AHF model in mice. Their findings revealed that 3-genes iPSC-based therapy not only improved hepatic functions and animal survival, but also improved CCl4-induced HE. After Chen's group (Chen et al., 2012), there have been only limited reports addressing the functionality of hepatic cells derived from hiPSCs/hPSCs (Takayama, 2015).

\section{Alzheimer's Disease (AD)}

Alzheimer's disease is characterized by the progressive deterioration of cognitive functions such as memory and mental processing. Most cases of $\mathrm{AD}$ are sporadic, but about $1-2 \%$ are genetically linked with the early onset (EOAD) of dementia. There are two major histopathological hallmarks in the brain of $\mathrm{AD}$ patients, the deposition of extracellular SPs composed of the $\mathrm{A} \beta$ peptide, and neurofibrillary tangles, which are intracellular inclusions of hyperphosphorylated tau protein in selective regions of the brain (Sidoryk-Wegrzynowicz et al., 2011). SPs are deposits of extracellular $A \beta$ protein derived from $A \beta 42$, a peptide fragment of 42 amino acid residues derived from the sequential step of proteolytic processing of amyloid precursor protein by $\beta$ and $\gamma$ secretase. As the disease progresses, synaptic loss and neuronal death become prominent, which consequently lead to the shrinkage of the brain.

The best-studied risk factor for sporadic, LOAD is the presence of ApoE (APOE \&4), a protein involved in lipid metabolism. The presence of one APOE $\varepsilon 4$ allele increases the risk of LOAD by threefold while two alleles of APOE $\varepsilon 4$ can increase the risk for late-onset $\mathrm{AD}$ by 12 -fold. Multiple studies from various populations have confirmed the increase in LOAD is caused by the presence of an APOE$\varepsilon 4$ allele. In contrast, $\mathrm{APOE}-\varepsilon 2$, another variation of this allele, confers protection against developing $\mathrm{AD}$. A recent finding suggests that astrocytes play a significant role in the clearance of the $A \beta$ peptide thus preventing the formation of plaques in the healthy brain (Wyss-Coray et al., 2003; Li et al., 2011). The precise mechanism by which astrocytes recognize and degrade $A \beta$ is not known, but ApoE which is primarily expressed in astrocytes and to a lesser extent in microglia has been proposed to be responsible for this cellular action (Koistinaho et al., 2004; Castellano et al., 2011). The importance of APOE $\varepsilon 4$ in AD has been well established, although further studies are needed to understand the exact molecular mechanism that leads to an increased susceptibility for $\mathrm{AD}$. 
TABLE 5 | Use of human astrocytes generated from pluripotent stem cells for disease modeling and pathology research.

\begin{tabular}{|c|c|c|c|c|}
\hline Disorder & Phenotypes & Culture methods & Potential applications & Reference \\
\hline \multirow[t]{2}{*}{$\begin{array}{l}\text { Amyotrophic lateral } \\
\text { sclerosis (ALS) }\end{array}$} & $\begin{array}{l}\text { Down regulation of VAPB } \\
\text { expression, failure of motor } \\
\text { neurons }\end{array}$ & $\begin{array}{l}\text { By either direct reprogramming } \\
\text { or iPSC-derived NPCs }\end{array}$ & $\begin{array}{l}\text { Generated functional astroglia from human } \\
\text { induced pluripotent stem cells (iPSCs) } \\
\text { carrying an ALS-causing TDP-43 mutation }\end{array}$ & Serio et al., 2013 \\
\hline & & & $\begin{array}{l}\text { Human iPSC-derived astrocytes showed an } \\
\text { increase in Cx43 protein, }\end{array}$ & Almad et al., 2016 \\
\hline Rett syndrome (RTT) & $\begin{array}{l}\text { Fewer synapses, reduced } \\
\text { dendritic spine density, and } \\
\text { soma size }\end{array}$ & iPSC-derived NPCs & $\begin{array}{l}\text {-RTT-iPSCs showed the recapitulation of } \\
R T T \text { phenotypes. } \\
\text {-MeCP2 seems to have an essential } \\
\text { function in astrocytes }\end{array}$ & Dajani et al., 2013 \\
\hline Alzheimer disease (AD) & $\begin{array}{l}\text { Intracellular accumulation of } \\
A \beta \text {, increased ROS } \\
\text { production, ER stress }\end{array}$ & $\begin{array}{l}\text { Embryoid body formation by } \\
\text { dual smad molecules }\end{array}$ & & Kondo et al., 2013 \\
\hline Huntington disorder & $\begin{array}{l}\text { Trinucleotide repeat } \\
\text { expansion (CAG) in exon } 1 \\
\text { of huntington }(\mathrm{HTT})\end{array}$ & iPSC-derived NPCs & $\begin{array}{l}\text {-Generated adult form of HD (F-HD-iPSCs). } \\
\text {-ldentified a cellular vacuolation phenotype } \\
\text { similar to HD patients. }\end{array}$ & Juopperi et al., 2012 \\
\hline
\end{tabular}

Another significant aspect of $\mathrm{AD}$ pathogenesis is the interaction of microglia and astrocytes through the production of neurotoxic molecules. The role of astrocytes in inflammatory processes is complicated to address, though activated astrocytes are capable of phagocytosis. Activated astrocytes are characterized by hypertrophic somata in neurodegenerative diseases. The process of astrocyte activation results in reactive gliosis, which appears in late stage $\mathrm{AD}$. Reactive astrogliosis in $\mathrm{AD}$ can be triggered by various elements, including damaged neuronal signaling and extracellular deposition of the $\beta$-amyloid peptide. Once substantial accumulation occurs, astrocytes themselves undergo apoptosis resulting in the formation of amyloid plaques positive for GFAP and S100 $\beta$. Recently, iPSC-derived neurons from different patients were found to show different accumulation of $A \beta$ oligomers in AD models (Israel et al., 2012; Kondo et al., 2013) Therefore the use of iPSC-derived AD model can act as a testing platform for the optimal pharmacological regimen.

\section{Neuromyelitis Optica (NMO)}

Neuromyelitis Optica is a primary astrocytopathy disease affecting the CNS. NMO was first described in the 19th century and was long considered to be a variant of multiple sclerosis. Pathological descriptions such as the frequent occurrence of necrosis with cavitation are used to distinguish NMO from multiple sclerosis (Marignier et al., 2010). The disease is commonly associated with diffuse cerebral white matter lesions that resemble acute disseminated encephalomyelitis, and severe demyelination affecting the optic nerve and spinal cord. The evidence of this disease reveals the loss of neurons and astrocytic damage (Wingerchuk et al., 2007). AQP-4 is one of the most valuable tools for the diagnosis of NMO (Lennon et al., 2004), and a novel potential therapeutic approach using a recombinant monoclonal antiAQP4 antibody that selectively inhibits NMO-IgG binding to AQP-4 has been proposed (Tradtrantip et al., 2012). This study demonstrates a direct way in understanding the pathogenesis of autoimmune disease of $\mathrm{NMO}$ in mouse models.

Indeed, several studies have highlighted the relevance of stem cells derived astrocytes in disease modeling. Some examples are mentioned below (Table 5).

\section{CONCLUSION}

Astrocytes are fundamentally involved in various neurological diseases as a consequence of either loss or gain of astrocyte function, and it is now clear that these disorders arise from a complex combination of abnormalities in either neurons, glial cells or immune cells. Recent data suggests that early stages of neurodegenerative disease, for example, are associated with loss of synaptic connectivity, imbalances in neurotransmitter homeostasis, leading to neuronal death probably through increased excitotoxicity in later stages. In the end-stage of neurodegeneration, astrocytes become activated and contribute to neuroinflammatory components of neurodegeneration. Therefore to understand the principles of neurodegeneration and its biology, hPSC-derived neuroglia could serve as a promising tool for creating in vivo-like cellular models for dementia and neurological disorders such as ALS, AxD where patient's neuronal tissue is highly inaccessible.

Neural precursors derived from hPSCs represent an attractive tool for the in vitro generation of various neural cell types. In this present review, we have performed a side-to-side comparison of existing protocols and evaluated the astrocyte differentiation based on cellular morphology and gene expression analyses from the human PSCs. Thus RG-like cells expressing RG markers BLBP, GLAST, vimentin, and GFAP could serve as a robust tool for an efficient astroglial generation. We hope 
this review has shed light on the current progress of astrocyte research.

\section{AUTHOR CONTRIBUTIONS}

AC has written the manuscript, HA and JK edited the manuscript, $\mathrm{AD}$ and $\mathrm{ML}$ approved the manuscript. All authors read and approved the final version.

\section{FUNDING}

This work was supported by grants from EU FP7 projects (STEMCAM PIAP-GA-2009-251186; STEMMAD, PIAPP-GA2012-324451; Epihealth, HEALTH-2012-F2-278418; Epihealth

\section{REFERENCES}

Abbott, N. J., Rönnbäck, L., and Hansson, E. (2006). Astrocyte-endothelial interactions at the blood-brain barrier. Nat. Rev. Neurosci. 7, 41-53. doi: $10.1038 / \mathrm{nrn} 1824$

Agulhon, C., Sun, M. Y., Murphy, T., Myers, T., Lauderdale, K., and Fiacco, T. A. (2012). Calcium signaling and gliotransmission in normal vs. reactive astrocytes. Front. Pharmacol. 3:139. doi: 10.3389/fphar.2012.00139

Alexandra Adam, S., Schnell, O., Pöschl, J., Eigenbrod, S., Kretzschmar, H. A., Tonn, J. C., et al. (2012). ALDH1A1 is a marker of astrocytic differentiation during brain development and correlates with better survival in glioblastoma patients. Brain Pathol. 22, 788-797. doi: 10.1111/j.1750-3639.2012. 00592.x

Almad, A. A., Doreswamy, A., Gross, S. K., Richard, J. P., Huo, Y., Haughey, N., et al. (2016). Connexin 43 in astrocytes contributes to motor neuron toxicity in amyotrophic lateral sclerosis. Glia $64,1154-1169$. doi: 10.1002/glia. 22989

Anand, K. S., Garg, J., Valecha, Y., and Makar, R. S. (2007). Megalencephalic leukoencephalopathy with subcortical cyst. J. Indian Acad. Clin. Med. 8, 250252. doi: 10.1177/08830738030180091201

Anderson, M. A., Burda, J. E., Ren, Y., Ao, Y., O'Shea, T. M., Kawaguchi, R., et al. (2016). Astrocyte scar formation aids central nervous system axon regeneration. Nature 532, 195-200. doi: 10.1038/nature17623

Anthony, T. E., Klein, C., Fishell, G., and Heintz, N. (2004). Radial glia serve as neuronal progenitors in all regions of the central nervous system. Neuron 41, 881-890. doi: 10.1016/S0896-6273(04)00140-0

Araque, A., and Navarrete, M. (2010). Glial cells in neuronal network function. Philos. Trans. R. Soc. Lond. B. Biol. Sci. 365, 2375-2381. doi: 10.1098/rstb.2009.0313

Araque, A., Parpura, V., Sanzgiri, R. P., and Haydon, P. G. (1999). Tripartite synapses: glia, the unacknowledged partner. Trends Neurosci. 22, 208-215. doi: 10.1016/S0166-2236(98)01349-6

Azevedo, F. A. C., Carvalho, L. R. B., Grinberg, L. T., Farfel, J. M., Ferretti, R. E. L., Leite, R. E. P., et al. (2009). Equal numbers of neuronal and nonneuronal cells make the human brain an isometrically scaled-up primate brain. J. Comp. Neurol. 513, 532-541. doi: 10.1002/cne.21974

Barbeito, L. H., Pehar, M., Cassina, P., Vargas, M. R., Peluffo, H., Viera, L., et al. (2004). A role for astrocytes in motor neuron loss in amyotrophic lateral sclerosis. Brain Res. Rev. 47, 263-274. doi: 10.1016/j.brainresrev.2004. 05.003

Barry, D., and McDermott, H. (2005). Differentiation of radial glia from radial precursor cells and transformation into astrocytes in the developing rat spinal cord. Glia 50, 187-197. doi: 10.1002/glia.20166

Bélanger, M., Allaman, I., and Magistretti, P. J. (2011). Brain energy metabolism: focus on Astrocyte-neuron metabolic cooperation. Cell Metab. 14, 724-738. doi: 10.1016/j.cmet.2011.08.016

Betizeau, M., Cortay, V., Patti, D., Pfister, S., Gautier, E., Bellemin-Ménard, A., et al. (2013). Precursor diversity and complexity of lineage relationships
Net PITN-GA-2012-317146; EU-ToxRisk H2020-PHC2015-681002) and Research Center of Excellence 114763/2016/FEKUT.

\section{ACKNOWLEDGMENTS}

We are thankful to Ms. Lone Neelchen Rösingh for her valuable help in the preparation of our manuscript and grateful to Mr. Sujay Thangaraj for his help in drawing tools. The authors would also like to thank Mr. Cormac Murphy and Dr. Sharon Mortimer for language editing of the manuscript. We apologize to those authors whose excellent work we have not cited due to space restrictions.

in the outer subventricular zone of the primate. Neuron $80,442-457$. doi: 10.1016/j.neuron.2013.09.032

Bonni, A., Sun, Y., Nadal-Vicens, M., Bhatt, A., Frank, D. A., Rozovsky, I., et al. (1997). Regulation of gliogenesis in the central nervous system by the JAK-STAT signaling pathway. Science 278, 477-483. doi: 10.1126/science.278.5337.477

Brenner, M., Goldman, J. E., Quinlan, R. A., Messing, A., Parpura, V., Haydon, P. G., et al. (2009). "Alexander disease: a genetic disorder of astrocytes," in Astrocytes in (Patho)Physiology of the Nervous System, eds P. G. Haydon and V. Parpura (New York, NY: Springer.) doi: 10.1007/978-0-387-79492-1_24

Brignone, M. S., Lanciotti, A., Visentin, S., De Nuccio, C., Molinari, P., Camerini, S., et al. (2014). Megalencephalic leukoencephalopathy with subcortical cysts protein-1 modulates endosomal $\mathrm{pH}$ and protein trafficking in astrocytes: relevance to MLC disease pathogenesis. Neurobiol. Dis. 66, 1-18. doi: 10.1016/j.nbd.2014.02.003

Brown, R. C., Mark, K. S., Egleton, R. D., Huber, J. D., Burroughs, A. R., and Davis, T. P. (2003). Protection against hypoxia-induced increase in blood-brain barrier permeability: role of tight junction proteins and NFkappaB. J. Cell Sci. 116, 693-700. doi: 10.1242/jcs.00264

Burette, A., Belliot, G., Albuisson, E., and Romand, R. (1998). Localization of neurotrophin-3-like immunoreactivity in the rat cochlear nucleus. Microsc. Res. Tech. 41, 224-233. doi: 10.1002/(SICI)1097-0029(19980501)41:3<224::AIDJEMT6 $>3.0$. CO;2-T

Burger, P. C., and Scheithauer, B. W. (1993). Tumors of the Central Nervous System. Dordrecht: Springer.

Bushong, E. A., Martone, M. E., Jones, Y. Z., and Ellisman, M. H. (2002). Protoplasmic astrocytes in CA1 stratum radiatum occupy separate anatomical domains. J. Neurosci. 22, 183-192.

Butterworth, R. F. (2010). Altered glial-neuronal crosstalk: cornerstone in the pathogenesis of hepatic encephalopathy. Neurochem. Int. 57, 383-388. doi: 10.1016/j.neuint.2010.03.012

Cahoy, J. D., Emery, B., Kaushal, A., Foo, L. C., Zamanian, J. L., Christopherson, K. S., et al. (2008). A transcriptome database for astrocytes, neurons, and oligodendrocytes: a new resource for understanding brain development and function. J. Neurosci. 28, 264-278. doi: 10.1523/JNEUROSCI.4178-07.2008

Caiazzo, M., Giannelli, S., Valente, P., Lignani, G., Carissimo, A., Sessa, A., et al. (2014). Direct conversion of fibroblasts into functional astrocytes by defined transcription factors. Stem Cell Rep. 4, 25-36. doi: 10.1016/j.stemcr.2014. 12.002

Carlén, M., Meletis, K., Göritz, C., Darsalia, V., Evergren, E., Tanigaki, K., et al. (2009). Forebrain ependymal cells are Notch-dependent and generate neuroblasts and astrocytes after stroke. Nat. Neurosci. 12, 259-267. doi: $10.1038 / \mathrm{nn} .2268$

Carpenter, M. K., Inokuma, M. S., Denham, J., Mujtaba, T., Chiu, C. P., and Rao, M. S. (2001). Enrichment of neurons and neural precursors from human embryonic stem cells. Exp. Neurol. 172, 383-397. doi: 10.1006/exnr.2001.7832

Castellano, J. M., Kim, J., Stewart, F. R., Jiang, H., DeMattos, R. B., Patterson, B. W., et al. (2011). Human apoE isoforms differentially 
regulate brain amyloid- $\beta$ peptide clearance. Sci. Transl. Med. 3:89ra57. doi: 10.1126/scitranslmed.3002156

Cavanaugh, S. E., Pippin, J. J., and Barnard, N. D. (2014). Animal models of alzheimer disease: historical pitfalls and a path forward. ALTEX 31, 279-302. doi: 10.14573/altex.1310071

Chambers, S. M., Fasano, C. A., Papapetrou, E. P., Tomishima, M., Sadelain, M., and Studer, L. (2009). Highly efficient neural conversion of human ES and iPS cells by dual inhibition of SMAD signaling. Nat. Biotechnol. 27, 275-280. doi: $10.1038 /$ nbt0509-485a

Chaudhry, F. A., Lehre, K. P., van Lookeren Campagne, M., Ottersen, O. P., Danbolt, N. C., and Storm-Mathisen, J. (1995). Glutamate transporters in glial plasma membranes: highly differentiated localizations revealed by quantitative ultrastructural immunocytochemistry. Neuron 15, 711-720. doi: 10.1016/08966273(95)90158-2

Chen, H., Qian, K., Du, Z., Cao, J., Petersen, A., Liu, H., et al. (2014). Modeling ALS with iPSCs reveals that mutant SOD1 misregulates neurofilament balance in motor neurons. Cell Stem Cell 14, 796-809. doi: 10.1016/j.stem.2014. 02.004

Chen, Y.-F., Tseng, C.-Y., Wang, H.-W., Kuo, H.-C., Yang, V. W., and Lee, O. K. (2012). Rapid generation of mature hepatocyte-like cells from human induced pluripotent stem cells by an efficient three-step protocol. Hepatology 55, 1193-1203. doi: 10.1002/hep.24790

Chestkov, I. V., Vasilieva, E. A., Illarioshkin, S. N., Lagarkova, M. A., and Kiselev, S. L. (2014). Patient-specific induced pluripotent stem cells for SOD1associated amyotrophic lateral sclerosis pathogenesis studies. Acta Naturae 6, 54-60.

Chi, L., Ke, Y., Luo, C., Li, B., Gozal, D., Kalyanaraman, B., et al. (2006). Motor neuron degeneration promotes neural progenitor cell proliferation, migration, and neurogenesis in the spinal cords of amyotrophic lateral sclerosis mice. Stem Cells 24, 34-43. doi: 10.1634/stemcells. 2005-0076

Clarke, L. E., and Barres, B. A. (2013). Emerging roles of astrocytes in neural circuit development. Nat. Rev. Neurosci. 14, 311-321. doi: 10.1038/nrn3484

Colombo, J. A., Yanez, A., Puissant, V., and Lipina, S. (1995). Long, interlaminar astroglial cell processes in the cortex of adult monkeys. J. Neurosci. Res. 40, 551-556. doi: 10.1002/jnr.490400414

Coulter, D. A., and Eid, T. (2012). Astrocytic regulation of glutamate homeostasis in epilepsy. Glia 60, 1215-1226. doi: 10.1002/glia.22341

Cui, M., Aras, R., Christian, W. V., Rappold, P. M., Hatwar, M., Panza, J., et al. (2009). The organic cation transporter-3 is a pivotal modulator of neurodegeneration in the nigrostriatal dopaminergic pathway. Proc. Natl. Acad. Sci. U.S.A. 106, 8043-8048. doi: 10.1073/pnas.0900358106

Cummings, J. L., Morstorf, T., and Zhong, K. (2014). Alzheimer's disease drugdevelopment pipeline: few candidates, frequent failures. Alzheimers Res. Ther. 6:37. doi: $10.1186 /$ alzrt269

Czepiel, M., Balasubramaniyan, V., Schaafsma, W., Stancic, M., Mikkers, H., Huisman, C., et al. (2011). Differentiation of induced pluripotent stem cells into functional oligodendrocytes. Glia 59, 882-892. doi: 10.1002/glia. 21159

Dajani, R., Koo, S.-E., Sullivan, G. J., and Park, I.-H. (2013). Investigation of Rett syndrome using pluripotent stem cells. J. Cell. Biochem. 114, 2446-2453. doi: $10.1002 /$ jcb. 24597

Danbolt, N. C. (2001). Glutamate uptake. Prog. Neurobiol. 65, 1-105. doi: 10.1016/S0301-0082(00)00067-8

Deiters, V. S., and Guillery, R. W. (2013). Otto Friedrich Karl Deiters (1834-1863). J. Comp. Neurol. 521, 1929-1953. doi: 10.1002/cne.23316

Deloulme, J. C., Raponi, E., Gentil, B. J., Bertacchi, N., Marks, A., Labourdette, G., et al. (2004). Nuclear expression of S100B in oligodendrocyte progenitor cells correlates with differentiation toward the oligodendroglial lineage and modulates oligodendrocytes maturation. Mol. Cell. Neurosci. 27, 453-465. doi: 10.1016/j.mcn.2004.07.008

Demars, M., Hu, Y.-S., Gadadhar, A., and Lazarov, O. (2010). Impaired neurogenesis is an early event in the etiology of familial Alzheimer's disease in transgenic mice. J. Neurosci. Res. 88, 2103-2117. doi: 10.1002/jnr.22387

Deneen, B., Ho, R., Lukaszewicz, A., Hochstim, C. J., Gronostajski, R. M., and Anderson, D. J. (2006). The transcription factor NFIA controls the onset of gliogenesis in the developing spinal cord. Neuron 52, 953-968. doi: 10.1016/j.neuron.2006.11.019
Dietrich, J., Noble, M., and Mayer-Proschel, M. (2002). Characterization of A2B5+ glial precursor cells from cryopreserved human fetal brain progenitor cells. Glia 40, 65-77. doi: 10.1002/glia.10116

Dimou, L., and Götz, M. (2014). Glial cells as progenitors and stem cells: new roles in the healthy and diseased brain. Physiol. Rev. 94, 709-737. doi: 10.1152/physrev.00036.2013

Diniz, L. P., Almeida, J. C., Tortelli, V., Lopes, C. V., Setti-Perdigão, P., Stipursky, J., et al. (2012). Astrocyte-induced synaptogenesis is mediated by transforming growth factor $\beta$ signaling through modulation of $\mathrm{d}$-serine levels in cerebral cortex neurons. J. Biol. Chem. 287, 41432-41445. doi: 10.1074/jbc.M112.380824

Doetsch, F., García-Verdugo, J. M., and Alvarez-Buylla, A. (1997). Cellular composition and three-dimensional organization of the subventricular germinal zone in the adult mammalian brain. J. Neurosci. 17, 5046-5061.

Dong, X. X., Wang, Y., and Qin, Z. H. (2009). Molecular mechanisms of excitotoxicity and their relevance to pathogenesis of neurodegenerative diseases. Acta Pharmacol. Sin. 30, 379-387. doi: 10.1038/Aps.2009.24

Duan, L., Peng, C. Y., Pan, L., and Kessler, J. (2015). Human pluripotent stem cell-derived radial glia recapitulate developmental events and provide real-time access to cortical neurons and astrocytes. Stem Cells Transl. Med. 4, 1-11. doi: 10.5966/sctm.2014-0137

Elkabetz, Y., Panagiotakos, G., Al Shamy, G., Socci, N. D., Tabar, V., and Studer, L. (2008). Human ES cell-derived neural rosettes reveal a functionally distinct early neural stem cell stage. Genes Dev. 22, 152-165. doi: 10.1101/gad.1616208

Elroy-Stein, O., and Schiffmann, R. (2014). "Vanishing white matter disease," in Rosenberg's Molecular and Genetic Basis of Neurological and Psychiatric Disease, 5th Edn, eds R. N. Rosenberg and J. M. Pascual (Amsterdam: Elsevier), 1015-1030. doi: 10.1016/B978-0-12-410529-4.00086-3

Emdad, L., D'Souza, S. L., Kothari, H. P., Qadeer, Z. A., and Germano, I. M. (2012). Efficient differentiation of human embryonic and induced pluripotent stem cells into functional astrocytes. Stem Cells Dev. 21, 404-410. doi: $10.1089 / \mathrm{scd} .2010 .0560$

Emsley, J. G., and Macklis, J. D. (2006). Astroglial heterogeneity closely reflects the neuronal-defined anatomy of the adult murine CNS. Neuron Glia Biol. 2, 175-186. doi: 10.1017/S1740925X06000202

Ennas, M. G., Cocchia, D., Silvetti, E., Sogos, V., Riva, A., Torelli, S., et al. (1992). Immunocompetent cell markers in human fetal astrocytes and neurons in culture. J. Neurosci. Res. 32, 424-436. doi: 10.1002/jnr.490320314

Eroglu, C., and Barres, B. A. (2010). Regulation of synaptic connectivity by glia. Nature 468, 223-231. doi: 10.1038/nature09612

Espuny-Camacho, I., Michelsen, K. A., Gall, D., Linaro, D., Hasche, A., Bonnefont, J., et al. (2013). Pyramidal neurons derived from human pluripotent stem cells integrate efficiently into mouse brain circuits in vivo. Neuron 77, 440-456. doi: 10.1016/j.neuron.2012.12.011

Farmer, W. T., Abrahamsson, T., Chierzi, S., Lui, C., Zaelzer, C., Jones, E. V., et al. (2016). Neurons diversify astrocytes in the adult brain through sonic hedgehog signaling. Science 351, 849-854. doi: 10.1126/science.aab3103

Fatemi, S. H., Folsom, T. D., Reutiman, T. J., and Lee, S. (2008). Expression of astrocytic markers aquaporin 4 and connexin 43 is altered in brains of subjects with autism. Synapse 62, 501-507. doi: 10.1002/syn.20519

Felipo, V., and Butterworth, R. F. (2002). Neurobiology of ammonia. Prog. Neurobiol. 67, 259-279. doi: 10.1016/S0301-0082(02)00019-9

Fietz, S. A., Kelava, I., Vogt, J., Wilsch-Bräuninger, M., Stenzel, D., Fish, J. L., et al. (2010). OSVZ progenitors of human and ferret neocortex are epithelial-like and expand by integrin signaling. Nat. Neurosci. 13, 690-699. doi: 10.1038/nn.2553

Florio, M., and Huttner, W. B. (2014). Neural progenitors, neurogenesis and the evolution of the neocortex. Development 141, 2182-2194. doi: 10.1242/dev.090571

Fox, I. J., Paucar, A. A., Nakano, I., Mottahedeh, J., Dougherty, J. D., and Kornblum, H. I. (2004). Developmental expression of glial fibrillary acidic protein mRNA in mouse forebrain germinal zones-implications for stem cell biology. Brain Res. Dev. Brain Res. 153, 121-125. doi: 10.1016/j.devbrainres.2004.07.011

Franke, H., and Kittner, H. (2001). Morphological alterations of neurons and astrocytes and changes in emotional behavior in pentylenetetrazol-kindled rats. Pharmacol. Biochem. Behav. 70, 291-303. doi: 10.1016/S0091-3057(01)00612-8

Freeman, M. R. (2010). Specification and morphogenesis of astrocytes. Science 330, 774-778. doi: 10.1126/science.1190928

Fuller, G. N., and Burger, P. C. (1992). "Central nervous system," in Histology for Pathologists, ed. S. S. Sternberg (New York, NY: Raven Press), 145-167. 
Ge, W.-P., Miyawaki, A., Gage, F. H., Jan, Y. N., and Jan, L. Y. (2012). Local generation of glia is a major astrocyte source in postnatal cortex. Nature 484, 376-380. doi: 10.1038/nature10959

Gee, J. R., and Keller, J. N. (2005). Astrocytes: regulation of brain homeostasis via apolipoprotein E. Int. J. Biochem. Cell Biol. 37, 1145-1150. doi: 10.1016/j.biocel.2004.10.004

Ghandour, M. S., Vincendon, G., and Gombos, G. (1980). Astrocyte and oligodendrocyte distribution in adult rat cerebellum: an immunohistological study. J. Neurocytol. 9, 637-646. doi: 10.1007/BF01205030

Gorris, R., Fischer, J., Erwes, K. L., Kesavan, J., Peterson, D. A., Alexander, M., et al. (2015). Pluripotent stem cell-derived radial glia-like cells as stable intermediate for efficient generation of human oligodendrocytes. Glia 63, 2152-2167. doi: 10.1002/glia.22882

Götz, M., and Huttner, W. B. (2005). The cell biology of neurogenesis. Nat. Rev. Mol. Cell Biol. 6, 777-788. doi: 10.1038/nrm1739

Götz, M., Sirko, S., Beckers, J., and Irmler, M. (2015). Reactive astrocytes as neural stem or progenitor cells: in vivo lineage, In vitro potential, and Genome-wide expression analysis. Glia 63, 1452-1468. doi: 10.1002/glia.22850

Gross, R. E., Mehler, M. F., Mabie, P. C., Zang, Z., Santschi, L., and Kessler, J. A. (1996). Bone morphogenetic proteins promote astroglial lineage commitment by mammalian subventricular zone progenitor cells. Neuron $17,595-606$. doi: 10.1016/S0896-6273(00)80193-2

Guillemin, G., Boussin, F. D., Croitoru, J., Franck-Duchenne, M., Le Grand, R., Lazarini, F., et al. (1997). Obtention and characterization of primary astrocyte and microglial cultures from adult monkey brains. J. Neurosci. Res. 49, 576-591. doi: 10.1002/(SICI)1097-4547(19970901)49:5 < 576::AID-JNR8> 3.0.CO;2-8

Gurney, M., Pu, H., Chiu, A., Dal Canto, M., Polchow, C., Alexander, D., et al. (1994). Motor neuron degeneration in mice that express a human $\mathrm{Cu}, \mathrm{Zn}$ superoxide dismutase mutation. Science 264, 1772-1775. doi: $10.1126 /$ science. 8209258

Haas, C., and Fischer, I. (2013). Human astrocytes derived from glial restricted progenitors support regeneration of the injured spinal cord. J. Neurotrauma 30, 1035-1052. doi: 10.1089/neu.2013.2915

Hachem, S., Aguirre, A., Vives, V., Marks, A., Gallo, V., and Legraverend, C. (2005). Spatial and temporal expression of S100B in cells of oligodendrocyte lineage. Glia 51, 81-97. doi: 10.1002/glia.20184

Halassa, M. M., Fellin, T., and Haydon, P. G. (2007). The tripartite synapse: roles for gliotransmission in health and disease. Trends Mol. Med. 13, 54-63. doi: 10.1016/j.molmed.2006.12.005

Hamilton, N. B., and Attwell, D. (2010). Do astrocytes really exocytose neurotransmitters? Nat. Rev. Neurosci. 11, 227-238. doi: 10.1038/nrn2803

Hansen, D. V., Lui, J. H., Parker, P. R. L., and Kriegstein, A. R. (2010). Neurogenic radial glia in the outer subventricular zone of human neocortex. Nature 464, 554-561. doi: 10.1038/nature08845

Hartfuss, E., Galli, R., Heins, N., and Götz, M. (2001). Characterization of CNS precursor subtypes and radial glia. Dev. Biol. 229, 15-30. doi: 10.1006/dbio.2000.9962

Hayashi, K., Hashimoto, M., Koda, M., Naito, A. T., Murata, A., Okawa, A., et al. (2011). Increase of sensitivity to mechanical stimulus after transplantation of murine induced pluripotent stem cell-derived astrocytes in a rat spinal cord injury model. J. Neurosurg. Spine 15, 582-593. doi: 10.3171/2011.7.SPINE 10775

Hong, Y. K., and Chen, C. (2011). Wiring and rewiring of the retinogeniculate synapse. Curr. Opin. Neurobiol. 21, 228-237. doi: 10.1016/j.conb.2011.02.007

Howard, B., Chen, Y., and Zecevic, N. (2006). Cortical progenitor cells in the developing human telencephalon. Glia 53, 57-66. doi: 10.1002/glia.20259

Hu, B.-Y., Weick, J. P., Yu, J., Ma, L.-X., Zhang, X.-Q., Thomson, J. A., et al. (2010). Neural differentiation of human induced pluripotent stem cells follows developmental principles but with variable potency. Proc. Natl. Acad. Sci. U.S.A. 107, 4335-4340. doi: 10.1073/pnas.0910012107

Israel, M. A., Yuan, S. H., Bardy, C., Reyna, S. M., Mu, Y., Herrera, C., et al. (2012). Probing sporadic and familial Alzheimer's disease using induced pluripotent stem cells. Nature 482, 216-220. doi: 10.1038/nature10821

Itsykson, P., Ilouz, N., Turetsky, T., Goldstein, R. S., Pera, M. F., Fishbein, I., et al. (2005). Derivation of neural precursors from human embryonic stem cells in the presence of noggin. Mol. Cell. Neurosci. 30, 24-36. doi: 10.1016/j.mcn.2005.05.004
Jha, B. S., Rao, M., and Malik, N. (2015). Motor neuron differentiation from pluripotent stem cells and other intermediate proliferative precursors that can be discriminated by lineage specific reporters. Stem Cell Rev. Rep. 11, 194-204. doi: 10.1007/s12015-014-9541-0

Jiang, P., Chen, C., Wang, R., Chechneva, O. V., Chung, S.-H., Rao, M. S., et al. (2013). hESC-derived Olig2+ progenitors generate a subtype of astroglia with protective effects against ischaemic brain injury. Nat. Commun. 4:2196. doi: 10.1038/ncomms3196

Johnson, M. A., Weick, J. P., Pearce, R. A., and Zhang, S.-C. (2007). Functional neural development from human embryonic stem cells: accelerated synaptic activity via astrocyte coculture. J. Neurosci. 27, 3069-3077. doi: 10.1523/JNEUROSCI.4562-06.2007

Juopperi, T. A., Kim, W., Chiang, C.-H., Yu, H., Margolis, R. L., Ross, C. A., et al. (2012). Astrocytes generated from patient induced pluripotent stem cells recapitulate features of Huntington's disease patient cells. Mol. Brain 5:17. doi: 10.1186/1756-6606-5-17

Kageyama, R., Ohtsuka, T., Hatakeyama, J., and Ohsawa, R. (2005). Roles of bHLH genes in neural stem cell differentiation. Exp. Cell Res. 306, 343-348. doi: 10.1016/j.yexcr.2005.03.015

Kageyama, R., Ohtsuka, T., and Kobayashi, T. (2008). Roles of Hes genes in neural development. Dev. Growth Differ. 50(Suppl. 1), S97-S103. doi: 10.1111/j.1440169X.2008.00993.x

Kang, K., and Song, M. R. (2010). Diverse FGF receptor signaling controls astrocyte specification and proliferation. Biochem. Biophys. Res. Commun. 395, 324-329. doi: 10.1016/j.bbrc.2010.03.174

Kanski, R., Van Strien, M. E., Van Tijn, P., and Hol, E. M. (2014). A star is born: new insights into the mechanism of astrogenesis. Cell. Mol. Life Sci. 71, 433-447. doi: 10.1007/s00018-013-1435-9

Kiernan, M. C., Vucic, S., Cheah, B. C., Turner, M. R., Eisen, A., Hardiman, O., et al. (2011). Amyotrophic lateral sclerosis. Lancet 377, 942-955. doi: 10.1016/S01406736(10)61156-7

Kirkeby, A., Grealish, S., Wolf, D. A., Nelander, J., Wood, J., Lundblad, M., et al. (2012). Generation of regionally specified neural progenitors and functional neurons from human embryonic stem cells under defined conditions. Cell Rep. 1, 703-714. doi: 10.1016/j.celrep.2012.04.009

Kiskinis, E., Sandoe, J., Williams, L. A., Boulting, G. L., Moccia, R., Wainger, B. J., et al. (2014). Pathways disrupted in human ALS motor neurons identified through genetic correction of mutant SOD1. Cell Stem Cell 14, 781-795. doi: 10.1016/j.stem.2014.03.004

Kleiderman, S., Sá, J. V., Teixeira, A. P., Brito, C., Gutbier, S., Evje, L. G., et al. (2016). Functional and phenotypic differences of pure populations of stem cell-derived astrocytes and neuronal precursor cells. Glia 64, 695-715. doi: 10.1002/glia.22954

Koistinaho, M., Lin, S., Wu, X., Esterman, M., Koger, D., Hanson, J., et al. (2004). Apolipoprotein E promotes astrocyte colocalization and degradation of deposited amyloid-beta peptides. Nat. Med. 10, 719-726. doi: 10.1038/nm1058

Kondo, T., Asai, M., Tsukita, K., Kutoku, Y., Ohsawa, Y., Sunada, Y., et al. (2013). Modeling Alzheimer's disease with iPSCs reveals stress phenotypes associated with intracellular $\mathrm{A} \beta$ and differential drug responsiveness. Cell Stem Cell 12, 487-496. doi: 10.1016/j.stem.2013.01.009

Kowalczyk, T., Pontious, A., Englund, C., Daza, R. A. M., Bedogni, F., Hodge, R. D., et al. (2009). Intermediate neuronal progenitors (basal progenitors) produce pyramidal-projection neurons for all layers of cerebral cortex. Cereb. Cortex 19, 2439-2450. doi: 10.1093/cercor/bhn260

Krencik, R., and Ullian, E. M. (2013). A cellular star atlas: using astrocytes from human pluripotent stem cells for disease studies. Front. Cell. Neurosci. 7:25. doi: 10.3389/fncel.2013.00025

Krencik, R., Weick, J. P., Liu, Y., Zhang, Z.-J., and Zhang, S.-C. (2011). Specification of transplantable astroglial subtypes from human pluripotent stem cells. Nat. Biotechnol. 29, 528-534. doi: 10.1038/nbt.1877

Krencik, R., and Zhang, S. C. S.-C. (2011). Directed differentiation of functional astroglial subtypes from human pluripotent stem cells. Nat. Protoc. 6, 17101717. doi: $10.1038 /$ nprot.2011.405

Kriegstein, A. R., and Gotz, M. (2003). Radial glia diversity: a matter of cell fate. Glia 43, 37-43. doi: 10.1002/glia.10250

Kuegler, P. B., Baumann, B. A., Zimmer, B., Keller, S., Marx, A., Kadereit, S., et al. (2012). GFAP-independent inflammatory competence and trophic functions of 
astrocytes generated from murine embryonic stem cells. Glia 60, 218-228. doi: 10.1002/glia.21257

Kuegler, P. B., Zimmer, B., and Waldmann, T. (2010). Markers of murine embryonic and neural stem cells, neurons and astrocytes: reference points for developmental neurotoxicity testing. ALTEX 27, 17-42.

La Piana, R., Vanderver, A., van der Knaap, M., Roux, L., Tampieri, D., Brais, B., et al. (2012). Adult-onset vanishing white matter disease due to a novel EIF2B3 mutation. Arch. Neurol. 69, 765-768. doi: 10.1001/archneurol.2011.1942

Lafaille, F. G., Pessach, I. M., Zhang, S.-Y., Ciancanelli, M. J., Herman, M., Abhyankar, A., et al. (2012). Impaired intrinsic immunity to HSV-1 in human iPSC-derived TLR3-deficient CNS cells. Nature 491, 769-773. doi: 10.1038/nature 11583

LaMonica, B. E., Lui, J. H., Hansen, D. V., and Kriegstein, A. R. (2013). Mitotic spindle orientation predicts outer radial glial cell generation in human neocortex. Nat. Commun. 4:1665. doi: 10.1038/ncomms2647

Lanciotti, A., Brignone, M. S., Bertini, E., Petrucci, T. C., Aloisi, F., and Ambrosini, E. (2013). Astrocytes: emerging stars in leukodystrophy pathogenesis. Transl. Neurosci. 4, 144-164. doi: 10.2478/s13380-013-0118-1

Lee, S. C., Liu, W., Dickson, D. W., Brosnan, C. F., and Berman, J. W. (1993). Cytokine production by human fetal microglia and astrocytes. Differential induction by lipopolysaccharide and IL-1 beta. J. Immunol. 150, 2659-2667.

Lennon, V. A., Wingerchuk, D. M., Kryzer, T. J., Pittock, S. J., Lucchinetti, C. F., Fujihara, K., et al. (2004). A serum autoantibody marker of neuromyelitis optica: distinction from multiple sclerosis. Lancet 364, 2106-2112. doi: 10.1016/S0140-6736(04)17551-X

Lewitus, E., Kelava, I., and Huttner, W. B. (2013). Conical expansion of the outer subventricular zone and the role of neocortical folding in evolution and development. Front. Hum. Neurosci. 7:424. doi: 10.3389/fnhum.2013.00424

Li, C., Zhao, R., Gao, K., Wei, Z., Yin, M. Y., Lau, L. T., et al. (2011). Astrocytes: implications for neuroinflammatory pathogenesis of Alzheimer's disease. Curr. Alzheimer Res. 8, 67-80. doi: 10.2174/156720511794604543

Li, J., Hart, R. P., Mallimo, E. M., Swerdel, M. R., Kusnecov, A. W., and Herrup, K. (2013). EZH2-mediated H3K27 trimethylation mediates neurodegeneration in ataxia-telangiectasia. Nat. Neurosci. 16, 1745-1753. doi: 10.1038/nn.3564

Li, X.-J., Zhang, X., Johnson, M. A., Wang, Z.-B., Lavaute, T., and Zhang, S.C. (2009). Coordination of sonic hedgehog and Wnt signaling determines ventral and dorsal telencephalic neuron types from human embryonic stem cells. Development 136, 4055-4063. doi: 10.1242/dev.036624

Linnoila, J., and Chitnis, T. (2014). Balo concentric sclerosis in children: a case series. J. Child Neurol. 29, 603-607. doi: 10.1177/0883073813517294

Liu, H., and Zhang, S.-C. (2011). Specification of neuronal and glial subtypes from human pluripotent stem cells. Cell. Mol. Life Sci. 68, 3995-4008. doi: 10.1007/s00018-011-0770-y

Liu, X., Chen, J., Li, X., Gao, S., and Deng, M. (2014). [Generation of induced pluripotent stem cells from amyotrophic lateral sclerosis patientcarrying SOD1V14M mutation]. Zhonghua Yi Xue Za Zhi 94, 2143-2147.

Lough, M. E. (2012). Wernicke's encephalopathy: expanding the diagnostic toolbox. Neuropsychol. Rev. 22, 181-194. doi: 10.1007/s11065-0129200-7

Lovatt, D., Sonnewald, U., Waagepetersen, H. S., Schousboe, A., He, W., Lin, J. H.-C., et al. (2007). The transcriptome and metabolic gene signature of protoplasmic astrocytes in the adult murine cortex. J. Neurosci. 27, 1225512266. doi: 10.1523/JNEUROSCI.3404-07.2007

Lui, J. H., Hansen, D. V., and Kriegstein, A. R. (2011). Development and evolution of the human neocortex. Cell 146, 18-36. doi: 10.1016/j.cell.2011.06.030

Ma, D. K., Bonaguidi, M. A., Ming, G.-L., and Song, H. (2009). Adult neural stem cells in the mammalian central nervous system. Cell Res. 19, 672-682. doi: $10.1038 /$ cr.2009.56

Macvicar, B. A., and Newman, E. A. (2015). Astrocyte regulation of blood flow in the brain. Cold Spring Harb. Perspect. Biol. 7, 1-14. doi: 10.1101/cshperspect.a020388

Magistretti, P. J., Pellerin, L., Rothman, D. L., and Shulman, R. G. (1999). Energy on demand. Science 283, 496-497. doi: 10.1126/science.283. 5401.496

Marignier, R., Nicolle, A., Watrin, C., Touret, M., Cavagna, S., VarrinDoyer, M., et al. (2010). Oligodendrocytes are damaged by neuromyelitis optica immunoglobulin G via astrocyte injury. Brain 133, 2578-2591. doi: 10.1093/brain/awq177
Marín, O., and Rubenstein, J. L. (2001). A long, remarkable journey: tangential migration in the telencephalon. Nat. Rev. Neurosci. 2, 780-790. doi: $10.1038 / 35097509$

Messing, A., and Goldman, J. E. (2003). "Alexander disease," in Myelin Biology and Disorders, eds R. A. Lazzarini, J. W. Griffin, H. Lassman, K.-A. Nave, R. Miller, and B. D. Trapp (Amsterdam: Elsevier), 851-866. doi: 10.1016/B978012439510-7/50089-9

Meyer-Franke, A., Kaplan, M. R., Pfrieger, F. W., and Barres, B. A. (1995). Characterization of the signaling interactions that promote the survival and growth of developing retinal ganglion cells in culture. Neuron 15, 805-819. doi: 10.1016/0896-6273(95)90172-8

Miller, F. D., and Gauthier, A. S. (2007). Timing is everything: making neurons versus glia in the developing cortex. Neuron 54, 357-369. doi: 10.1016/j.neuron.2007.04.019

Ming, G., and Song, H. (2005). Adult neurogenesis in the mammalian central nervous system. Annu. Rev. Neurosci. 28, 223-250. doi: 10.1146/annurev.neuro.28.051804.101459

Mo, Z., Moore, A. R., Filipovic, R., Ogawa, Y., Kazuhiro, I., Antic, S. D., et al. (2007). Human cortical neurons originate from radial glia and neuron-restricted progenitors. J. Neurosci. 27, 4132-4145. doi: 10.1523/JNEUROSCI.011107.2007

Molofsk, A. V., Krenick, R., Ullian, E., Tsai, H. H., Deneen, B., Richardson, W. D., et al. (2012). Astrocytes and disease: a neurodevelopmental perspective. Genes Dev. 26, 891-907. doi: 10.1101/gad.188326.112

Moon, C., Yoo, J.-Y., Matarazzo, V., Sung, Y. K., Kim, E. J., and Ronnett, G. V (2002). Leukemia inhibitory factor inhibits neuronal terminal differentiation through STAT3 activation. Proc. Natl. Acad. Sci. U.S.A. 99, 9015-9020. doi: 10.1073/pnas. 132131699

Mormone, E., D'Sousa, S., Alexeeva, V., Bederson, M. M., and Germano, I. M. (2014). "Footprint-free" human induced pluripotent stem cell-derived astrocytes for in vivo cell-based therapy. Stem Cells Dev. 23, 2626-2636. doi: $10.1089 / \mathrm{scd} .2014 .0151$

Muratore, C. R., Srikanth, P., Callahan, D. G., and Young-Pearse, T. L. (2014). Comparison and optimization of hiPSC forebrain cortical differentiation protocols. PLoS ONE 9:e105807. doi: 10.1371/journal.pone.0105807

Nagao, M., Sugimori, M., and Nakafuku, M. (2007). Cross talk between notch and growth factor/cytokine signaling pathways in neural stem cells. Mol. Cell. Biol. 27, 3982-3994. doi: 10.1128/MCB.00170-07

Nakanishi, M., Niidome, T., Matsuda, S., Akaike, A., Kihara, T., and Sugimoto, H. (2007). Microglia-derived interleukin-6 and leukaemia inhibitory factor promote astrocytic differentiation of neural stem/progenitor cells. Eur. J. Neurosci. 25, 649-658. doi: 10.1111/j.1460-9568.2007.05309.x

Nakashima, K., Takizawa, T., Ochiai, W., Yanagisawa, M., Hisatsune, T., Nakafuku, M., et al. (2001). BMP2-mediated alteration in the developmental pathway of fetal mouse brain cells from neurogenesis to astrocytogenesis. Proc. Natl. Acad. Sci. U.S.A. 98, 5868-5873. doi: 10.1073/pnas.1011 09698

Nedergaard, M., Ransom, B., and Goldman, S. A. (2003). New roles for astrocytes: redefining the functional architecture of the brain. Trends Neurosci. 26, 523530. doi: $10.1016 /$ j.tins.2003.08.008

Nishiyama, A., Watanabe, M., Yang, Z., and Bu, J. (2002). Identity, distribution, and development of polydendrocytes: NG2-expressing glial cells. J. Neurocytol. 31, 437-455. doi: 10.1023/A:1025783412651

Noctor, S. C., Martinez-Cerdeño, V., and Kriegstein, A. R. (2008). Distinct behaviors of neural stem and progenitor cells underlie cortical neurogenesis. J. Comp. Neurol. 508, 28-44. doi: 10.1002/cne.21669

Oberheim, N. A., Goldman, S. A., and Nedergaard, M. (2012). Heterogeneity of astrocytic form and function. Methods Mol. Biol. 814, 23-45. doi: 10.1007/9781-61779-452-0_3

Oberheim, N. A., Takano, T., Han, X., He, W., Lin, J. H. C., Wang, F., et al. (2009). Uniquely hominid features of adult human astrocytes. J. Neurosci. 29, 3276-3287. doi: 10.1523/JNEUROSCI.4707-08.2009

Oberheim, N. A., Wang, X., Goldman, S., and Nedergaard, M. (2006). Astrocytic complexity distinguishes the human brain. Trends Neurosci. 29, 547-553. doi: 10.1016/j.tins.2006.08.004

Ogata, K., and Kosaka, T. (2002). Structural and quantitative analysis of astrocytes in the mouse hippocampus. Neuroscience 113, 221-233. doi: 10.1016/S03064522(02)00041-6 
Olude, M. A., Mustapha, O. A., Aderounmu, O. A., Olopade, J. O., and Ihunwo, A. O. (2015). Astrocyte morphology, heterogeneity, and density in the developing African giant rat (Cricetomys gambianus). Front. Neuroanat. 9:67. doi: 10.3389/fnana.2015.00067

Palm, T., Bolognin, S., Meiser, J., Nickels, S., Träger, C., Meilenbrock, R.-L., et al. (2015). Rapid and robust generation of long-term self-renewing human neural stem cells with the ability to generate mature astroglia. Sci. Rep. 5:16321. doi: 10.1038/srep 16321

Parameswaran, S., Balasubramanian, S., Babai, N., Qiu, F., Eudy, J. D., Thoreson, W. B., et al. (2010). Induced pluripotent stem cells generate both retinal ganglion cells and photoreceptors: therapeutic implications in degenerative changes in glaucoma and age-related macular degeneration. Stem Cells 28, 695-703. doi: 10.1002/stem.320

Parpura, V., and Verkhratsky, A. (2012). Astrocytes revisited: concise historic outlook on glutamate homeostasis and signaling. Croat. Med. J. 53, 518-528. doi: $10.3325 / \mathrm{cmj} .2012 .53 .518$

Paşca, A. M., Sloan, S. A., Clarke, L. E., Tian, Y., Makinson, C. D., Huber, N., et al. (2015). Functional cortical neurons and astrocytes from human pluripotent stem cells in 3D culture. Nat. Methods 12, 671-678. doi: 10.1038/nmeth.3415

Paulson, O. B., and Newman, E. A. (1987). Does the release of potassium from astrocyte endfeet regulate cerebral blood flow? Science 237, 896-898. doi: 10.1016/j.bbi.2008.05.010

Pellerin, L., Pellegri, G., Bittar, P. G., Charnay, Y., Bouras, C., Martin, J. L., et al. (1998). Evidence supporting the existence of an activity-dependent astrocyteneuron lactate shuttle. Dev. Neurosci. 20, 291-299. doi: 10.1159/000017324

Perea, G., Navarrete, M., and Araque, A. (2009). Tripartite synapses: astrocytes process and control synaptic information. Trends Neurosci. 32, 421-431. doi: 10.1016/j.tins.2009.05.001

Peters, A., Palay, S. L., and Webster, H. (1991). The Fine Structure of the Nervous System: Neurons and Their Supporting Cells. Oxford: Oxford University Press.

Pilz, G.-A., Shitamukai, A., Reillo, I., Pacary, E., Schwausch, J., Stahl, R., et al. (2013). Amplification of progenitors in the mammalian telencephalon includes a new radial glial cell type. Nat. Commun. 4:2125. doi: 10.1038/ ncomms 3125

Pollen, A. A., Nowakowski, T. J., Chen, J., Retallack, H., Sandoval-Espinosa, C., Nicholas, C. R., et al. (2015). Molecular identity of human outer radial glia during cortical development. Cell 163, 55-67. doi: 10.1016/j.cell.2015. 09.004

Pouya, A., Satarian, L., Kiani, S., Javan, M., and Baharvand, H. (2011). Human induced pluripotent stem cells differentiation into oligodendrocyte progenitors and transplantation in a rat model of optic chiasm demyelination. PLOS ONE 6:e27925. doi: 10.1371/journal.pone.0027925

Prust, M., Wang, J., Morizono, H., Messing, A., Brenner, M., Gordon, E., et al. (2011). GFAP mutations, age at onset, and clinical subtypes in Alexander disease. Neurology 77, 1287-1294. doi: 10.1212/WNL.0b013e3182 $309 f 72$

Regan, M. R., Huang, Y. H., Kim, Y. S., Dykes-Hoberg, M. I., Jin, L., Watkins, A. M., et al. (2007). Variations in promoter activity reveal a differential expression and physiology of glutamate transporters by glia in the developing and mature CNS. J. Neurosci. 27, 6607-6619. doi: 10.1523/JNEUROSCI.0790-07.2007

Reisin, H. D., and Colombo, J. A. (2004). Glial changes in primate cerebral cortex following long-term sensory deprivation. Brain Res. 1000, 179-182. doi: 10.1016/j.brainres.2003.11.029

Renner, N. A., Sansing, H. A., Inglis, F. M., Mehra, S., Kaushal, D., Lackner, A. A., et al. (2013). Transient acidification and subsequent proinflammatory cytokine stimulation of astrocytes induce distinct activation phenotypes. J. Cell. Physiol. 228, 1284-1294. doi: 10.1002/jcp.24283

Reubinoff, B. E., Itsykson, P., Turetsky, T., Pera, M. F., Reinhartz, E., Itzik, A., et al. (2001). Neural progenitors from human embryonic stem cells. Nat. Biotechnol. 19, 1134-1140. doi: 10.1038/nbt1201-1134

Reuss, B., and Unsicker, K. (2000). Survival and differentiation of dopaminergic mesencephalic neurons are promoted by dopamine-mediated induction of FGF-2 in striatal astroglial cells. Mol. Cell. Neurosci. 16, 781-792. doi: 10.1006/mcne.2000.0906

Rhee, Y. H., Ko, J. Y., Chang, M. Y., Yi, S. H., Kim, D., Kim, C. H., et al. (2011). Protein-based human iPS cells efficiently generate functional dopamine neurons and can treat a rat model of Parkinson disease. J. Clin. Invest. 121, 2326-2335. doi: 10.1172/JCI45794
Ricci, G., Volpi, L., Pasquali, L., Petrozzi, L., and Siciliano, G. (2009). Astrocyteneuron interactions in neurological disorders. J. Biol. Phys. 35, 317-336. doi: 10.1007/s10867-009-9157-9

Robel, S., Berninger, B., and Götz, M. (2011). The stem cell potential of glia: lessons from reactive gliosis. Nat. Rev. Neurosci. 12, 88-104. doi: 10.1038/nrn2978

Rodnight, R., Gonçalves, C. A., Wofchuk, S. T., and Leal, R. (1997). Control of the phosphorylation of the astrocyte marker glial fibrillary acidic protein (GFAP) in the immature rat hippocampus by glutamate and calcium ions: possible key factor in astrocytic plasticity. Braz. J. Med. Biol. Res. 30, 325-38.

Rosen, D. R., Siddique, T., Patterson, D., Figlewicz, D. A., Sapp, P., Hentati, A., et al. (1993). Mutations in $\mathrm{Cu} / \mathrm{Zn}$ superoxide dismutase gene are associated with familial amyotrophic lateral sclerosis. Nature 362, 59-62. doi: 10.1038/3620 $59 \mathrm{a} 0$

Rossi, D., Martorana, F., and Brambilla, L. (2011). Implications of gliotransmission for the pharmacotherapy of CNS disorders. CNS Drugs 25, 641-658. doi: 10.2165/11593090-000000000-00000

Rothstein, J. D., Van Kammen, M., Levey, A. I., Martin, L. J., and Kuncl, R. W. (1995). Selective loss of glial glutamate transporter GLT-1 in amyotrophic lateral sclerosis. Ann. Neurol. 38, 73-84. doi: 10.1002/ana.410380114

Rowitch, D. H., and Kriegstein, A. R. (2010). Developmental genetics of vertebrate glial-cell specification. Nature 468, 214-222. doi: 10.1038/nature09611

Rowland, L., and Shneider, N. (2001). Amyotrophic lateral sclerosis. N. Engl. J. Med. 344, 1688-1700. doi: 10.1056/NEJM200105313442207

Roybon, L., Lamas, N., Garcia-Diaz, A., Yang, E., Sattler, R., Jackson-Lewis, V., et al. (2013). Human stem cell-derived spinal cord astrocytes with defined mature or reactive phenotypes. Cell Rep. 4, 1035-1048. doi: 10.1016/j.celrep.2013.06.021

Sahlender, D. A., Savtchouk, I., and Volterra, A. (2014). What do we know about gliotransmitter release from astrocytes? Philos. Trans. R. Soc. Lond. B. Biol. Sci. 369:20130592. doi: 10.1098/rstb.2013.0592

Sánchez-Danés, A., Consiglio, A., Richaud, Y., Rodríguez-Pizà, I., Dehay, B., Edel, M., et al. (2012). Efficient generation of A9 midbrain dopaminergic neurons by lentiviral delivery of LMX1A in human embryonic stem cells and induced pluripotent stem cells. Hum. Gene Ther. 23, 56-69. doi: 10.1089/hum.2011.054

Santello, M., Bezzi, P., and Volterra, A. (2011). TNF $\alpha$ controls glutamatergic gliotransmission in the hippocampal dentate gyrus. Neuron 69, 988-1001. doi: 10.1016/j.neuron.2011.02.003

Saporta, M. A., Grskovic, M., and Dimos, J. T. (2011). Induced pluripotent stem cells in the study of neurological diseases. Stem Cell Res. Ther. 2:37. doi: $10.1186 /$ scrt78

Sareen, D., Gowing, G., Sahabian, A., Staggenborg, K., Paradis, R., Avalos, P., et al. (2014). Human neural progenitor cells generated from induced pluripotent stem cells can survive, migrate, and integrate in the rodent spinal cord. J. Comp. Neurol. 522, 2707-2728. doi: 10.1002/cne.23578

Schitine, C., Nogaroli, L., Costa, M. R., and Hedin-Pereira, C. (2015). Astrocyte heterogeneity in the brain: from development to disease. Front. Cell. Neurosci. 9:76. doi: 10.3389/fncel.2015.00076

Sechi, G., and Serra, A. (2007). Wernicke's encephalopathy: new clinical settings and recent advances in diagnosis and management. Lancet Neurol. 6, 442-455. doi: 10.1016/S1474-4422(07)70104-7

Serio, A., Bilican, B., Barmada, S. J., Ando, D. M., Zhao, C., Siller, R., et al. (2013). Astrocyte pathology and the absence of non-cell autonomy in an induced pluripotent stem cell model of TDP-43 proteinopathy. Proc. Natl. Acad. Sci. U.S.A. 110, 4697-4702. doi: 10.1073/pnas.1300398110

Shaltouki, A., Peng, J., Liu, Q., Rao, M. S., and Zeng, X. (2013). Efficient generation of astrocytes from human pluripotent stem cells in defined conditions. Stem Cells 31, 941-952. doi: 10.1002/stem.1334

Sheng, J., Yang, S., Xu, L., Wu, C., Wu, X., Li, A., et al. (2004). Bystin as a novel marker for reactive astrocytes in the adult rat brain following injury. Eur. J. Neurosci. 20, 873-884. doi: 10.1111/j.1460-9568.2004. 03567.x

Sherwood, C. C., Stimpson, C. D., Raghanti, M. A., Wildman, D. E., Uddin, M., Grossman, L. I., et al. (2006). Evolution of increased glia-neuron ratios in the human frontal cortex. Proc. Natl. Acad. Sci. U.S.A. 103, 13606-13611. doi: 10.1073/pnas.0605843103

Shi, Y., Kirwan, P., and Livesey, F. J. (2012). Directed differentiation of human pluripotent stem cells to cerebral cortex neurons and neural networks. Nat. Protoc. 7, 1836-1846. doi: 10.1038/nprot.2012.116 
Sidoryk-Wegrzynowicz, M., Wegrzynowicz, M., Lee, E., Bowman, A. B., and Aschner, M. (2011). Role of astrocytes in brain function and disease. Toxicol. Pathol. 39, 115-123. doi: 10.1177/0192623310385254

Sild, M., and Ruthazer, E. S. (2011). Radial glia: progenitor, pathway, and partner. Neuroscientist 17, 288-302. doi: 10.1177/1073858410385870

Slezak, M., and Pfrieger, F. W. (2003). New roles for astrocytes: regulation of CNS synaptogenesis. Trends Neurosci. 26, 531-535. doi: 10.1016/j.tins.2003.08.005

Sloan, S. A., and Barres, B. A. (2014). Looks can be deceiving: reconsidering the evidence for gliotransmission. Neuron 84, 1112-1115. doi: 10.1016/j.neuron.2014.12.003

Sofroniew, M. V., and Vinters, H. V. (2010). Astrocytes: biology and pathology. Acta Neuropathol. 119, 7-35. doi: 10.1007/s00401-009-0619-8

Song, M.-R., and Ghosh, A. (2004). FGF2-induced chromatin remodeling regulates CNTF-mediated gene expression and astrocyte differentiation. Nat. Neurosci. 7, 229-235. doi: 10.1038/nn1192

Sonnewald, U., Westergaard, N., and Schousboe, A. (1997). Glutamate transport and metabolism in astrocytes. Glia 21, 56-63. doi: 10.1002/(SICI)10981136(199709)21:1 < 56::AID-GLIA6> 3.0.CO;2-\#

Stevens, B., Allen, N. J., Vazquez, L. E., Howell, G. R., Christopherson, K. S., Nouri, N., et al. (2007). The classical complement cascade mediates CNS synapse elimination. Cell 131, 1164-1178. doi: 10.1016/j.cell.2007.10.036

Stipursky, J., Romão, L., Tortelli, V., Neto, V. M., and Gomes, F. C. A. (2011). Neuron-glia signaling: implications for astrocyte differentiation and synapse formation. Life Sci. 524-531. doi: 10.1016/j.lfs.2011.04.005

Stipursky, J., Spohr, T. C. L., Sousa, V. O., and Gomes, F. C. A. (2012). Neuronastroglial interactions in cell-fate commitment and maturation in the central nervous system. Neurochem. Res. 37, 2402-2418. doi: 10.1007/s11064-0120798-x

Stobart, J. L., and Anderson, C. M. (2013). Multifunctional role of astrocytes as gatekeepers of neuronal energy supply. Front. Cell. Neurosci. 7:38. doi: 10.3389/fncel.2013.00038

Sun, W., McConnell, E., Pare, J.-F., Xu, Q., Chen, M., Peng, W., et al. (2013). Glutamate-dependent neuroglial calcium signaling differs between young and adult brain. Science 339, 197-200. doi: 10.1126/science.1226740

Tabar, V., Panagiotakos, G., Greenberg, E. D., Chan, B. K., Sadelain, M., Gutin, P. H., et al. (2005). Migration and differentiation of neural precursors derived from human embryonic stem cells in the rat brain. Nat. Biotechnol. 23, 601-606. doi: $10.1038 / \mathrm{nbt} 1088$

Takahashi, K., Tanabe, K., Ohnuki, M., Narita, M., Ichisaka, T., Tomoda, K., et al. (2007). Induction of pluripotent stem cells from adult human fibroblasts by defined factors. Cell 131, 861-872. doi: 10.1016/j.cell.2007.11.019

Takahashi, K., and Yamanaka, S. (2006). Induction of pluripotent stem cells from mouse embryonic and adult fibroblast cultures by defined factors. Cell 126, 663-676. doi: 10.1016/j.cell.2006.07.024

Takayama, K. (2015). Establishment of a method of hepatocyte differentiation from human pluripotent stem cells for innovative drug development. Yakugaku Zasshi 135, 1141-1146. doi: 10.1248/yakushi.15-00194

Tanga, X., Zhoua, L., Wagnera, A. M., Marchettob, M. C. N., Muotric, A. R., Gageb, F. H., et al. (2013). Astroglial cells regulate the developmental timeline of human neurons differentiated from induced pluripotent stem cells. Stem Cell Res. 11, 743-757. doi: 10.1016/j.biotechadv.2011.08.021.Secreted

Tarassishin, L., Suh, H. S., and Lee, S. C. (2014). LPS and IL-1 differentially activate mouse and human astrocytes: role of CD14. Glia 62, 999-1013. doi: 10.1002/glia.22657

Thomsen, E. R., Mich, J. K., Yao, Z., Hodge, R. D., Doyle, A. M., Jang, S., et al. (2016). Fixed single-cell transcriptomic characterization of human radial glial diversity. Nat. Methods 13, 87-93. doi: 10.1038/nmeth.3629

Tidyman, W. E., and Rauen, K. A. (2009). "The RASopathies: syndromes of Ras/MAPK pathway dysregulation," in Neurofibromatosis Type 1: Molecular and Cellular Biology, eds D. N. Cooper and M. Upadhyaya (Berlin: Springer Science and Business Media), 497-511. doi: 10.1007/978-3-642-32864-0_32

Tokumoto, Y., Ogawa, S., Nagamune, T., and Miyake, J. (2010). Comparison of efficiency of terminal differentiation of oligodendrocytes from induced pluripotent stem cells versus embryonic stem cells in vitro. J. Biosci. Bioeng. 109, 622-628. doi: 10.1016/j.jbiosc.2009.11.013

Tradtrantip, L., Zhang, H., Anderson, M. O., Saadoun, S., Phuan, P.-W., Papadopoulos, M. C., et al. (2012). Small-molecule inhibitors of NMO-IgG binding to aquaporin-4 reduce astrocyte cytotoxicity in neuromyelitis optica. FASEB J. 26, 2197-2208. doi: 10.1096/fj.11-201608

Tucker, B. A., Park, I.-H., Qi, S. D., Klassen, H. J., Jiang, C., Yao, J., et al. (2011). Transplantation of adult mouse iPS cell-derived photoreceptor precursors restores retinal structure and function in degenerative mice. PLOS ONE 6:e18992. doi: 10.1371/journal.pone.0018992

Turner, B. J., and Talbot, K. (2008). Transgenics, toxicity and therapeutics in rodent models of mutant SOD1-mediated familial ALS. Prog. Neurobiol. 85, 94-134. doi: 10.1016/j.pneurobio.2008.01.001

Ullian, E. M., Sapperstein, S. K., Christopherson, K. S., and Barres, B. A. (2001). Control of synapse number by glia. Science 291, 657-661. doi: $10.1126 /$ science.291.5504.657

Vecino, E., Rodriguez, F. D., Ruzafa, N., Pereiro, X., and Sharma, S. C. (2015). Glianeuron interactions in the mammalian retina. Prog. Retin. Eye Res. 51, 1-39. doi: 10.1016/j.preteyeres.2015.06.003

Ventura, R. E., and Goldman, J. E. (2007). Dorsal radial glia generate olfactory bulb interneurons in the postnatal murine brain. J. Neurosci. 27, 4297-4302. doi: 10.1523/JNEUROSCI.0399-07.2007

Wang, A., Tang, Z., Park, I.-H., Zhu, Y., Patel, S., Daley, G. Q., et al. (2011). Induced pluripotent stem cells for neural tissue engineering. Biomaterials 32, 5023-5032. doi: 10.1016/j.biomaterials.2011.03.070

Wang, L., Colodner, K. J., and Feany, M. B. (2011). Protein misfolding and oxidative stress promote glial-mediated neurodegeneration in an Alexander disease model. J. Neurosci. 31, 2868-2877. doi: 10.1523/JNEUROSCI.341010.2011

Wang, Y., and Qin, Z.-H. (2010). Molecular and cellular mechanisms of excitotoxic neuronal death. Apoptosis 15, 1382-1402. doi: 10.1007/s10495-010-0481-0

Weiss, N., Miller, F., Cazaubon, S., and Couraud, P. O. (2009). The blood-brain barrier in brain homeostasis and neurological diseases. Biochim. Biophys. Acta 1788, 842-857. doi: 10.1016/j.bbamem.2008.10.022

Wen, S., Li, H., and Liu, J. (2009). Dynamic signaling for neural stem cell fate determination. Cell Adh. Migr. 3, 107-117. doi: 10.4161/cam.3.1.7602

Widestrand, A., Faijerson, J., Wilhelmsson, U., Smith, P. L. P., Li, L., Sihlbom, C., et al. (2007). Increased neurogenesis and astrogenesis from neural progenitor cells grafted in the hippocampus of GFAP-/- Vim-/- mice. Stem Cells 25, 2619-2627. doi: 10.1634/stemcells.2007-0122

Wingerchuk, D. M., Lennon, V. A., Lucchinetti, C. F., Pittock, S. J., and Weinshenker, B. G. (2007). The spectrum of neuromyelitis optica. Lancet Neurol. 6, 805-815. doi: 10.1016/S1474-4422(07)70216-8

Wyss-Coray, T., Loike, J. D., Brionne, T. C., Lu, E., Anankov, R., Yan, F., et al. (2003). Adult mouse astrocytes degrade amyloid-beta in vitro and in situ. Nat. Med. 9, 453-457. doi: 10.1038/nm838

Yan, Y., Yang, D., Zarnowska, E. D., Du, Z., Werbel, B., Valliere, C., et al. (2005). Directed differentiation of dopaminergic neuronal subtypes from human embryonic stem cells. Stem Cells 23, 781-790. doi: 10.1634/stemcells. 2004-0365

Yu, K., Lu, D., Rowland, N. E., and Raizada, M. K. (1996). Angiotensin II regulation of tyrosine hydroxylase gene expression in the neuronal cultures of normotensive and spontaneously hypertensive rats. Endocrinology 137, 35663576. doi: 10.1210/endo.137.8.8754788

Zhang, J., and Jiao, J. (2015). Molecular biomarkers for embryonic and adult neural stem cell and neurogenesis. Biomed Res. Int. 2015:727542. doi: $10.1155 / 2015 / 727542$

Zhang, S. C., Wernig, M., Duncan, I. D., Brüstle, O., and Thomson, J. A. (2001). In vitro differentiation of transplantable neural precursors from human embryonic stem cells. Nat. Biotechnol. 19, 1129-1133. doi: 10.1038/nbt1201-1129

Zhang, Y., Chen, K., Sloan, S. A., Bennett, M. L., Scholze, A. R., O’Keeffe, S., et al. (2014). An RNA-sequencing transcriptome and splicing database of glia, neurons, and vascular cells of the cerebral cortex. J. Neurosci. 34, 11929-11947. doi: 10.1523/JNEUROSCI.1860-14.2014

Zhang, Y., Sloan, S. A., Clarke, L. E., Caneda, C., Plaza, C. A., Blumenthal, P. D., et al. (2016). Purification and characterization of progenitor and mature human astrocytes reveals transcriptional and functional differences with mouse. Neuron 89, 37-53. doi: 10.1016/j.neuron.2015.11.013

Zhou, S., Szczesna, K., Ochalek, A., Kobolk, J., Varga, E., Nemes, C., et al. (2016). Neurosphere based differentiation of human IPSC improves astrocyte differentiation. Stem Cells Int. 2016, 1-15. doi: 10.1155/2016/4937689 
Zonta, M., Angulo, M. C., Gobbo, S., Rosengarten, B., Hossmann, K.-A., Pozzan, T., et al. (2003). Neuron-to-astrocyte signaling is central to the dynamic control of brain microcirculation. Nat. Neurosci. 6, 43-50. doi: 10.1038/nn980

Conflict of Interest Statement: The authors declare that the research was conducted in the absence of any commercial or financial relationships that could be construed as a potential conflict of interest.
Copyright (๔) 2016 Chandrasekaran, Avci, Leist, Kobolák and Dinnyés. This is an open-access article distributed under the terms of the Creative Commons Attribution License (CC BY). The use, distribution or reproduction in other forums is permitted, provided the original author(s) or licensor are credited and that the original publication in this journal is cited, in accordance with accepted academic practice. No use, distribution or reproduction is permitted which does not comply with these terms. 